\title{
Cartography of the Luna-21 landing site and Lunokhod-2 traverse area based on Lunar Reconnaissance Orbiter Camera images and surface archive TV-panoramas
}

\author{
I.P. Karachevtseva ${ }^{1}$, N.A. Kozlova ${ }^{1}$, A.A. Kokhanov ${ }^{1}$, A.E. Zubarev ${ }^{1}$, I.E. Nadezhdina ${ }^{1}$, \\ V.D. Patratiy ${ }^{1}$, A.A. Konopikhin ${ }^{1}$, A.T. Basilevsky ${ }^{1,2}$, A.M. Abdrakhimov ${ }^{2}$, J. Oberst ${ }^{1,3,4}$,

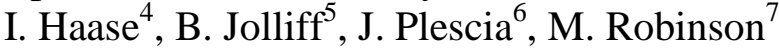

KEY WORDS: Moon, Soviet mission Luna-21, Lunokhod-2, LROC NAC, DEM, orthomosaic, GIS, surface analysis

\begin{abstract}
Lunar Reconnaissance Orbiter Camera (LROC) system consists of a Wide Angle Camera (WAC) and Narrow Angle Camera (NAC). NAC images $(\sim 0.5-1.7 \mathrm{~m} / \mathrm{pixel})$ reveal details of the Luna-21 landing site and Lunokhod-2 traverse area. We derived a Digital Elevation Model (DEM) and an orthomosaic for the study region using photogrammetric stereo processing techniques with NAC images. The DEM and mosaic allowed us to analyze the topography and morphology of the landing site area and to map the Lunokhod-2 rover route. The total range of topographic elevation along the traverse was found to be less than $144 \mathrm{~m}$; and the rover encountered slopes of up to 20 degrees. With the orthomosaic tied to the lunar reference frame, derived coordinates of the Lunokhod-2 landing module, its final position and overnight stop points. We identified the exact rover route by following its tracks and determined its total length as $39.16 \mathrm{~km}$, more than was estimated during the mission $(37 \mathrm{~km})$, which until recently was a distance record for planetary robotic rovers held for more than 40 years.
\end{abstract}

\section{Introduction}

Luna-21 landed on 16 January 1973 and deployed the roving vehicle Lunokhod-2 (Research of the Moon, 1973). The goals of the mission were to study the topography, geology, and morphology of the lunar surface, in particular, the transition between mare and highlands. Luna-21 touched down in Le Monnier crater, located on the eastern margin of the Serenitatis Basin; the lava that filled Mare Serenitatis also flooded the floor of this $61 \mathrm{~km}$ diameter crater (Fig. 1). 


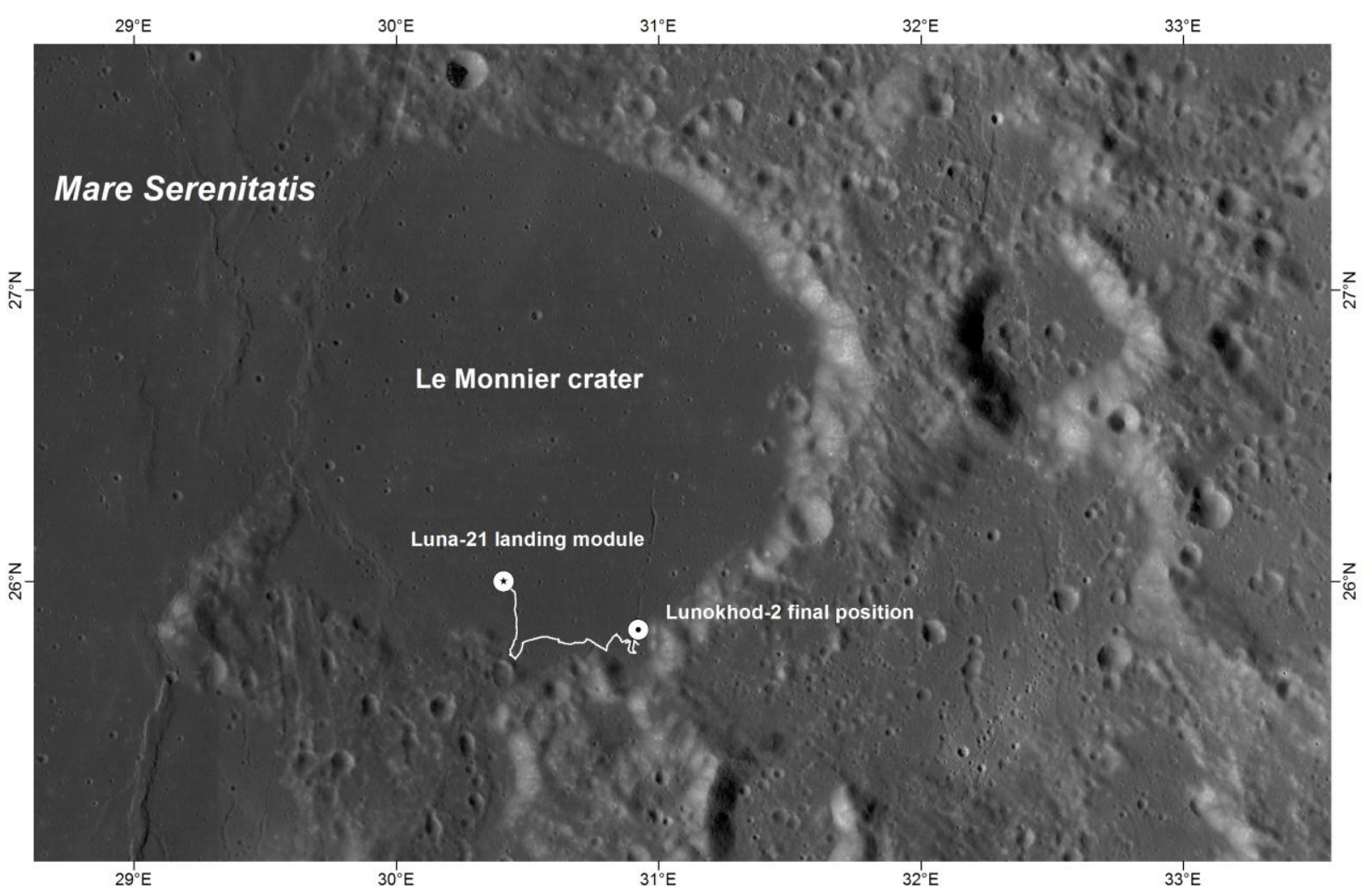

Figure 1. Map of crater Le Monnier with Luna-21 landing area. Background: WAC global mosaic (Scholten et al., 2012)

After an initial reconnaissance of the surrounding area (Fig. 2a), the Lunokhod-2 vehicle (Fig. 2b) descended to the lunar surface and started its journey and scientific experiments. Soon after landing the first panoramas and navigation images were taken and transmitted to Earth showing the surroundings, including the landing module (Fig. 3). Rover instruments, as well as equipment mounted on the first Soviet rover, Lunokhod-1 (Vinogradov et al., 1971; Barsukov et al., 1978), were to determine the physical and mechanical properties (Leonovich et al., 1971) and chemical composition (Kocharov et al., 1971) of the lunar regolith. Lunokhod-2, similar to Lunokhod-1, carried an X-ray telescope (Beygman et al., 1971), radiation detector (Vernov et al., 1971), and laser reflector for geodetic ranging experiments (Kokurin et al., 1978). As with Lunokhod-1, Lunokhod-2 was remotely controlled from the ground station in Crimea (Simferopol), but had a high degree of autonomy to enable it to operate for extended periods of time in the extreme conditions on the lunar surface (Kemurdzhian et al., 1993). 


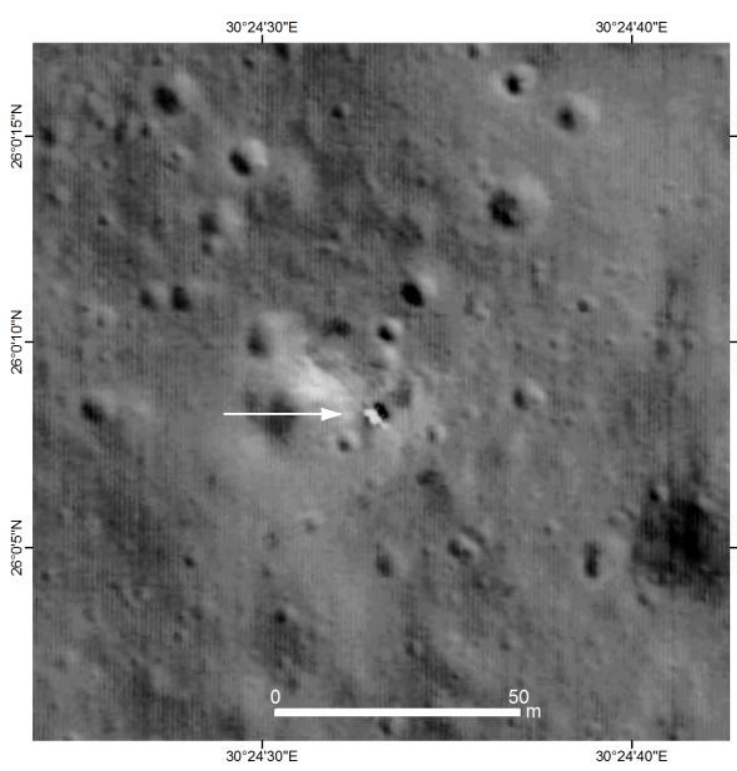

a)

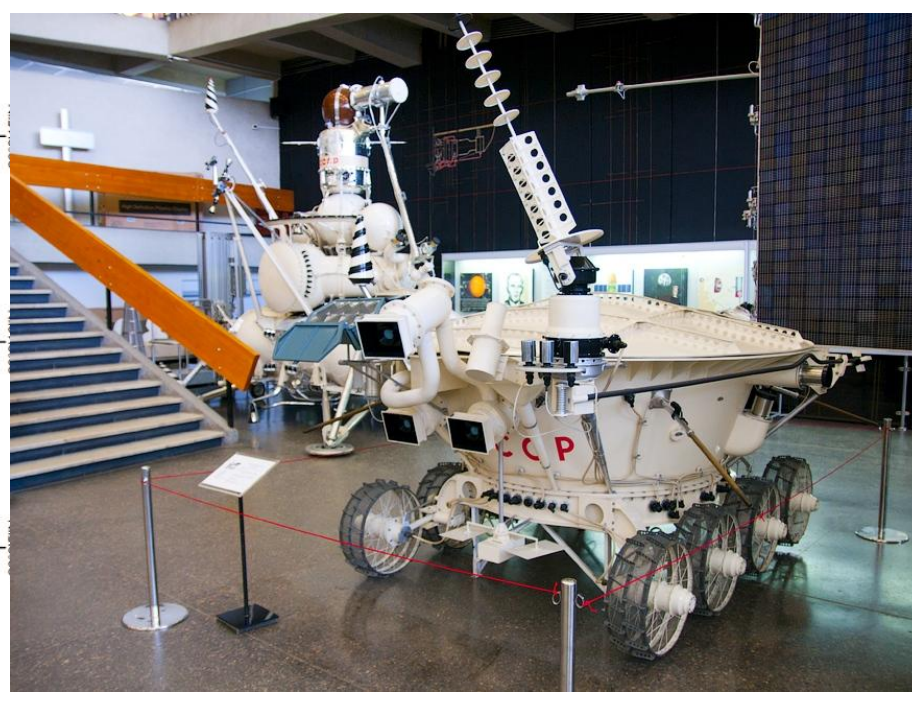

b)
61

62

Figure 2: a) Landing area of the Luna-21 mission and landing module, LROC NAC M122007650L (NASA/GSFC/ASU)); b) a model of Lunokhod-2 in The State Museum of the History of Cosmonautics named by K.E. Tsiolkovskiy (Moscow)

Lunokhod-2 survived for five lunar days and explored an area of approximately $180 \mathrm{~km}^{2}$ (estimated using a rectangle surrounding the entire route). Onboard camera systems (Selivanov et al., 1971) provided more than 90 panoramas (Fig. 3) and 80,000 navigation images.

On April 20, Lunokhod-2 drove into a relatively small but steep-sloped crater. During an attempt to exit the crater the solar panel accidently contacted the crater wall and scooped up and deposited soil onto the spacecraft radiator. On 10 May the temperature inside the spacecraft became critical and operation was stopped. Radio contact with the rover was lost a day later (11 May), due to overheating of the vehicle body (Dovgan, 2015). The mission was officially terminated 3 June 1973 (Huntress and Marov, 2011).

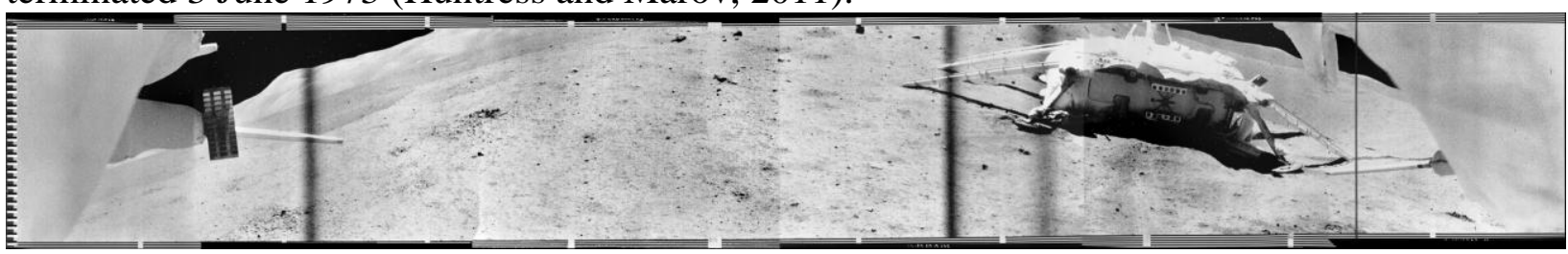

Figure 3. Archive lunar panorama (\#6-372) taken by Lunokhod-2 cameras on the first lunar day: the image, showing the Luna-21 landing module, is looking to the south; massifs of Le Monnier crater (left) are visible on the horizon $\sim 10-15 \mathrm{~km}$ to the east

High-resolution images obtained by the Lunar Reconnaissance Orbiter Camera (LROC) Narrow Angle Camera (NAC) (Robinson et al., 2010) have renewed interest in this historic rover mission. The Luna-21 lander and the rover can clearly be identified in the NAC images and rover wheel tracks along the traverse can be studied (Table 1). Recently, interest in the accomplishments of Lunokhod-2 was renewed when the length of the traverse of the Mars rover Opportunity exceeded the Lunokhod-2 record of $39.22 \mathrm{~km}$ in April 2014, a record that was held for more than 40 years by Lunokhod-2.

In this paper, we report mission details and the Lunokhod-2 traverse measurements based on the NAC images and associated ephemeris.

\section{Lunokhod-2}




\subsection{The rover construction and equipment}

Construction of Lunokhod-2 (Fig. 2b) was similar to that of Lunokhod-1, and consisted of the same self-propelled chassis and the sealed instrument compartment containing the scientific equipment. The total mass of Lunokhod-2 was $836 \mathrm{~kg}$ compared to $756 \mathrm{~kg}$ of Lunokhod-1 (Kemurdzhian et al., 1993). The top of the instrument compartment was equipped with a thermal radiator that could be covered by a large retractable lid during the night to reduce heat loss. The bottom side of the lid was equipped with solar arrays to supply power during the day. The solar cells were augmented with a combination of batteries and a polonium heat generator. New gallium arsenide solar arrays were deployed (instead of the previous siliceous photoelectric cells (http://www.laspace.ru/rus/luna21.html), providing a total capacity of $250 \mathrm{Ah}$ (Lunokhod-1 had $200 \mathrm{Ah})$.

In addition to the scientific equipment available on the Lunokhod-1, Lunokhod-2 had notable improvements (Kemurdzhian et al., 1993), as follows:

- A third navigation camera that allowed the operator crew to better focus on lunar surface (Dovgan, 2015);

- A Spectrometer to determine the chemical composition of the lunar regolith RIFMA-M (Roentgen Isotopic Fluorescent Method of Analysis) modified in comparison with RIFMA on board Lunokhod-1 (Kocharov and Viktorov, 1974);

- A ternary ferromagnetometer, mounted on a remote arm (1.5 meters length), that was to measure the magnetization of individual targets on the lunar surface (Dolginov et al., 1976);

- An astrophotometer for measuring of the luminosity of the sky at visible and ultraviolet wavelengths (Severny et al., 1975).

Lunokhod-2 had eight wheels, four on each side of the rover body. Each wheel consisted of three titanium rings (510 $\mathrm{mm}$ in diameter) and sixteen spokes wrapped in a metallic mesh. The wheels were $200 \mathrm{~mm}$ wide, and the spacing between wheels (track gauge) was 1600-1700 mm (Anisov et al., 1971). On soft surfaces the wheels were observed to penetrate deep into the regolith, and the wheels formed pronounced tracks along its traverse. The average specific pressure of the wheels on the ground (at a nominal depth in the regolith of $30 \mathrm{~mm}$ ) was 0.05 $\mathrm{kg} / \mathrm{cm}^{2}$ (Leonovich et al., 1978). The Lunokhod tracks are readily observed in the NAC frames because the grousers on the wheels significantly disturbed the soil. This disturbance is in marked contrast to the wheels of the Apollo lunar rover vehicles that did not have grousers and whose tracks are difficult to observe outside of the descent stage blast zones (Clegg et al., 2014), despite the fact that the wheel loading was similar.

Lunokhod-2 moved at two distinct speeds: $0.8 \mathrm{~km} /$ hour and $2.0 \mathrm{~km} /$ hour (Kemurdzhian et al., 1993). Turning of the vehicle was achieved by varying the rotation of the wheel on the right and left sides, respectively, and by changing the direction of their rotation. The turning radius of the rover in motion was typically $3 \mathrm{~m}$ with wheels turning at different speeds (Kemurdzhian et al., 1993). However, the rover could also turn in place (with its left and right wheels turning in opposite directions) within a radius of $0.8 \mathrm{~m}$. Areas where the rover turned in place can be seen readily in the NAC images.

The rear of the instrument compartment contained the heat source (polonium 210), the lifting and lowering mechanism for the lid (Kemurdzhian et al., 1993), as well as an experiment with a penetrator, PROP (Russian abbreviation from PRibor Otsenki Prokhodimosti, an instrument to measure trafficability) for assessments of physical and mechanical properties of the regolith (Cherkasov and Shvarev, 1975). Lunokhod-2 had an improved system of automatic locks that reacted in the event that the rover encountered dangerous slippage on steep slopes or excess voltage in the onboard power system.

Lunokhod-2 was equipped with a laser reflector, consisting of a block of 14 prisms ( $45 \mathrm{x}$ $20 \times 8 \mathrm{~cm}$ ) made of special heat-resisting glass and protected by multi-layer heat-insulating material (Kokurin et al., 1978). Since 1978 regular laser measurements of Lunokhod-2 carried 
out at the Crimean Astrophysical Observatory (CrAO) using a 2.6-meter telescope provided data on the distance to the Moon with an accuracy $25 \mathrm{~cm}$ (Kokurin, 2003). Results from the Lunar Laser Ranging (LLR) experiment provided important insights concerning the dynamics and interior of the Moon (Dickey et al., 1994). In addition, with the reflector coordinates established to the $\mathrm{cm}$ level, the laser reflector stations mark important geodetic reference points that define the currently used lunar coordinate systems (Archinal et al., 2011). At CrAO, a total of 1400 measurements were made using the Lunokhod-2 laser reflector; these observations were terminated in 1983 owing to cancellation of the Soviet lunar program (Kokurin, 2003). However, the Lunokhod-2 laser ranging was continued from other observatories (Williams et al., 2013), unlike the case of its predecessor on Lunokhod-1, which could not be recovered until its recognition in LRO images (Murphy et al., 2011). For unknown reasons, the return signal from Lunokhod-2 is at least five times weaker than that of Lunokhod-1. One possible explanation is that lunar dust is obscuring the reflectors (Murphy et al., 2010).

\subsection{Lunokhod-2 navigation system}

The number of Lunokhod cameras and their locations were chosen to give full view of the surrounding area, including horizon, the Sun, the Earth, as well as to provide information about the surface for safe movement.

Lunokhod-1 had two television cameras for navigation (abbreviated as "MKTV." This Russian abbreviation stands for "small frame television system") mounted at a height of $950 \mathrm{~mm}$ above the surface, the average height of a seated person (Selivanov et al., 1971). At the request of the operator crew (Dovgan, 2015), Lunokhod-2 was equipped with a third MKTV-camera mounted above the others, that would provide a view of the traverse ahead from the height of a standing person. This camera was a significant improvement and proved very useful when elements of the rover's attitude control system failed after landing. The driver and the crew had to navigate the rover based on the positions of the Sun and prominent relief features (Dovgan, 2015). The average speed of Lunokhod-2 was $340 \mathrm{~m}$ per hour (compared with $140 \mathrm{~m}$ per hour of Lunokhod-1). The high speed of Lunokhod-2 was obtained because operators benefitted from the experience of Lunokhod-1 (Petrov, 1978; Dovgan, 2015), as well as more frequent (closely spaced) navigation frames (approximately every $6 \mathrm{sec}$ vs. every $20 \mathrm{sec}$ for Lunokhod-1), which was enabled by a higher data transmission rate (Kemurdzhian et al., 1993).

In order to conduct the topographic and morphologic study of the lunar surface, the rover was also equipped with four panoramic scanner cameras: one horizontal and one vertical on each side (Selivanov et al., 1971). Horizontal camera made panoramas, the width is a bit more than $180^{\circ}$ (Fig. 3, Fig. 4a). Stereo images at some selected sites were obtained by taking panoramas from two positions of the Lunokhod (Rodionov et al, 1971). Based on stereo panoramas some topographic maps were obtained, which allowed to determine the steepness and slopes inside craters (Fig.6b). For photogrammetric processing and elevation measurements were used exterior orientation parameters - views of Sun, Earth and far surface objects like rim of Le Monnier crater (Rodionov et al., 1973).

Unfortunately, details on the orientation parameters including coordinates and tilts of the rover are not available and must be considered lost. To recover coordinates we implemented a method (Kozlova et al., 2014) that is based on a search for panorama observation points on LROC NAC images. The Lunokhod tilts have to be determined iteratively using archive panoramic images. Specially developed software (Zubarev et al., 2016), including digital palette (Fig. 4a), provides reconstruction of the horizon line with different values of tilts. After adjusting to the visible skyline on the panorama, the image is corrected for horizon geometric distortion (Fig. 4b). 


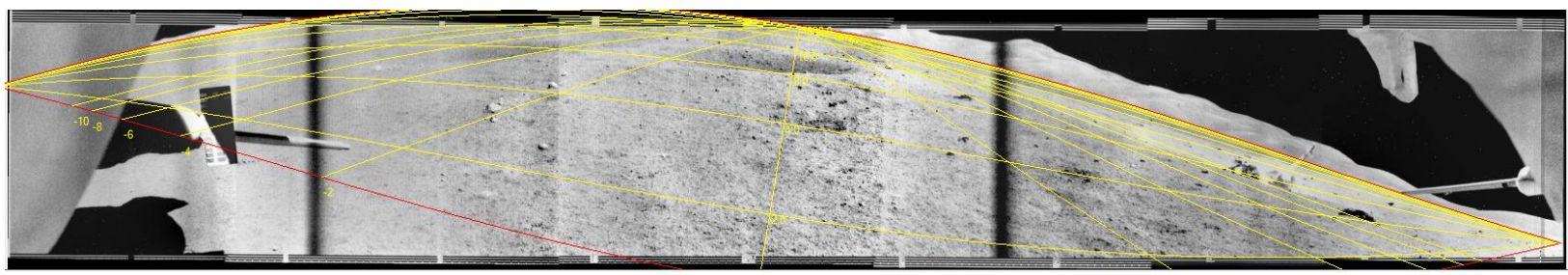

a)

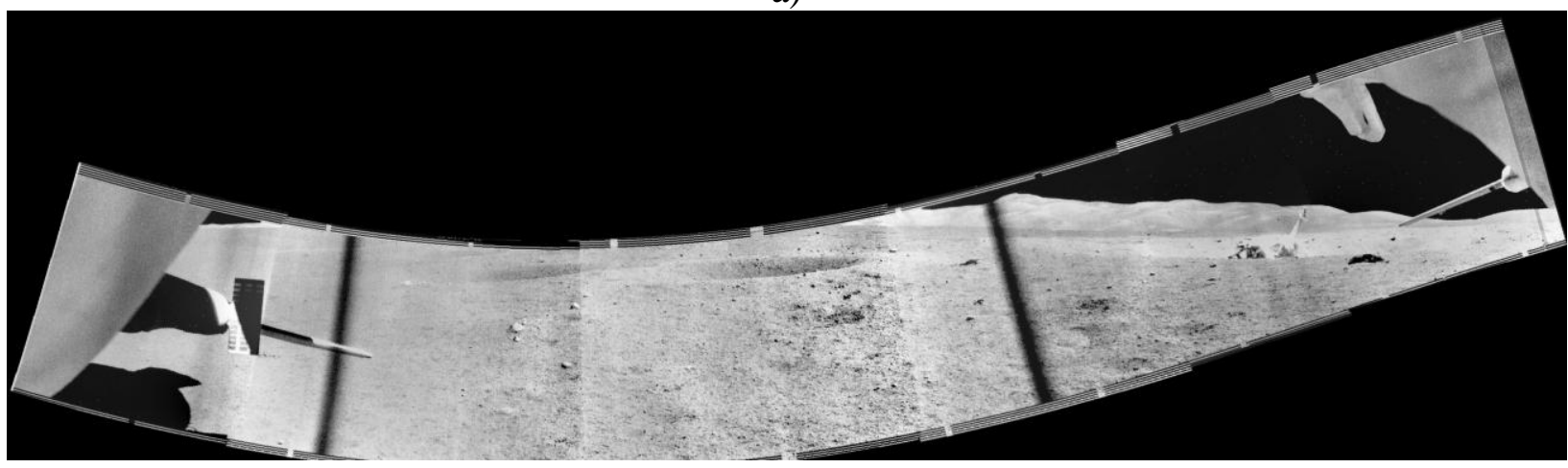

b)

Figure 4. The first Lunokhod-2 panorama taken from the lunar surface looking to the east (\#6368). A small crater and landing module (right) resting on the flat mare plain are seen in the foreground while the highland mountains composing the rim of Le Monnier crater can be seen in the background: a) image with superimposed coordinate grid for tilt measurements; b) image corrected for horizon curvature.

\subsection{Previous reconstruction of the route}

The original operations map of the Lunokhod-2 route (Fig. 5) based on traverse measurements during the mission, is currently held by the Lavochkin Research and Production Association Museum (http://www.laspace.ru/rus/museum.php). This map was compiled using photogrammetry and geodesy techniques that were initiated in the MIIGAiK Aerial Survey Department by Boris Nepoklonov in 1966. Later in the frame of navigation tasks of the Lunokhod-1 mission (Rodionov et al., 1971), the methodology was improved in the Space Research Institute of the Russian Academy of Science (Rodionov, 1999).

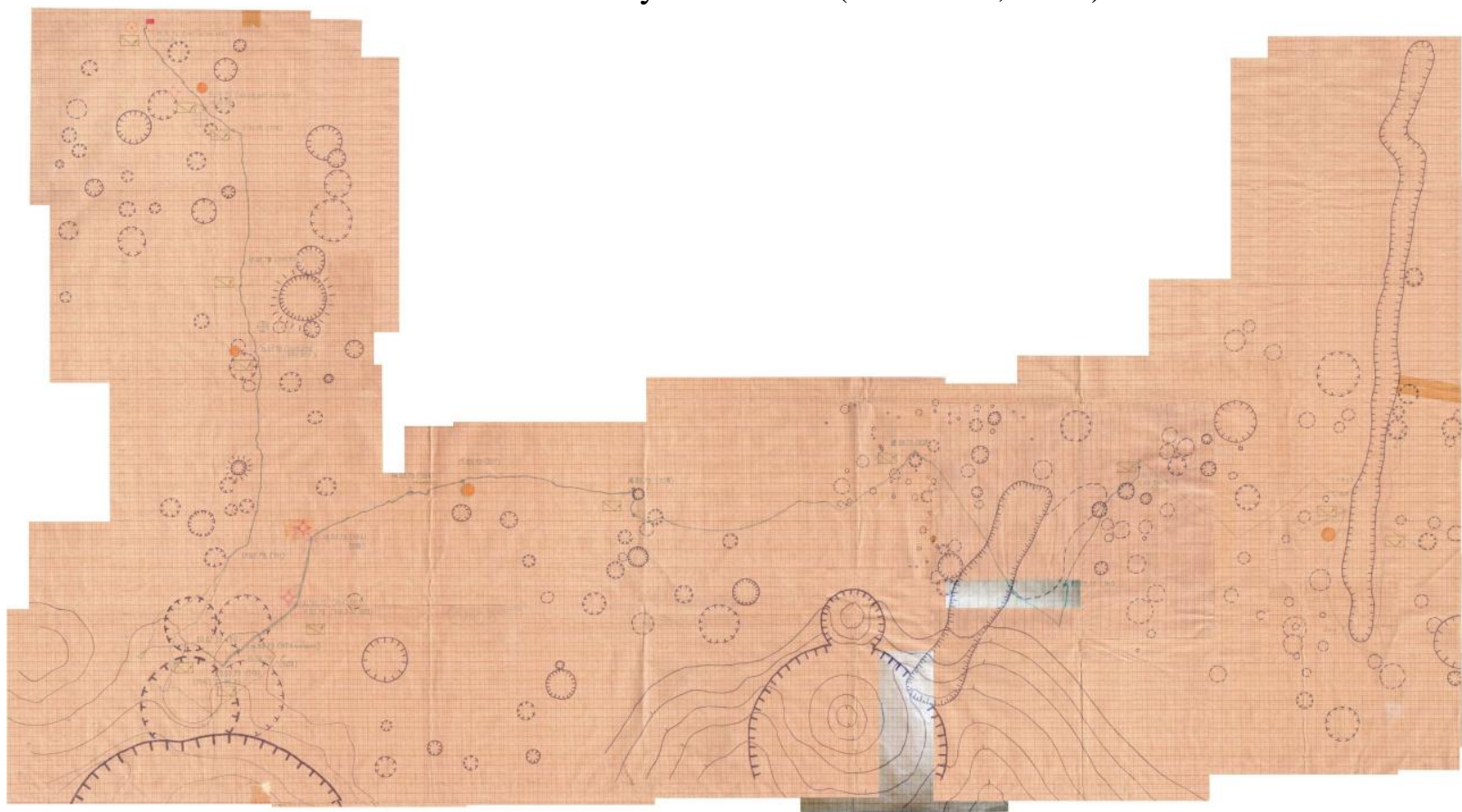

Figure 5. Historic operations map of the Lunokhod-2 traverse, compiled during the mission 
Using a combination of individual topographic maps of small study areas derived from operative panorama processing based on coordinate observations and navigation measurements, various maps of the Lunokhod-2 route were produced by the Nepoklonov group (Rodionov et al., 1973), including a topographic map of the southwest part of route (Fig. 6a), a relief map of an intensively studied small crater (Fig. 6b), and a topographic sketch map of the entire working area (Fig. 7); the last of these maps was published later (Kemurdzhian et al.,1978). The maps show craters and depressions, central hills of craters, individual boulders, and areas with scattered small rocks along the route (Lipskiy and Rodionova, 1978). The landing site, locations where samples were taken for the chemical analyses of the regolith, selected points for panoramic and stereoscopic surveys, rover stop points of RIFMA, and magnetic experiments have been marked. For our new analysis these maps provided important information (See Table 6-7).

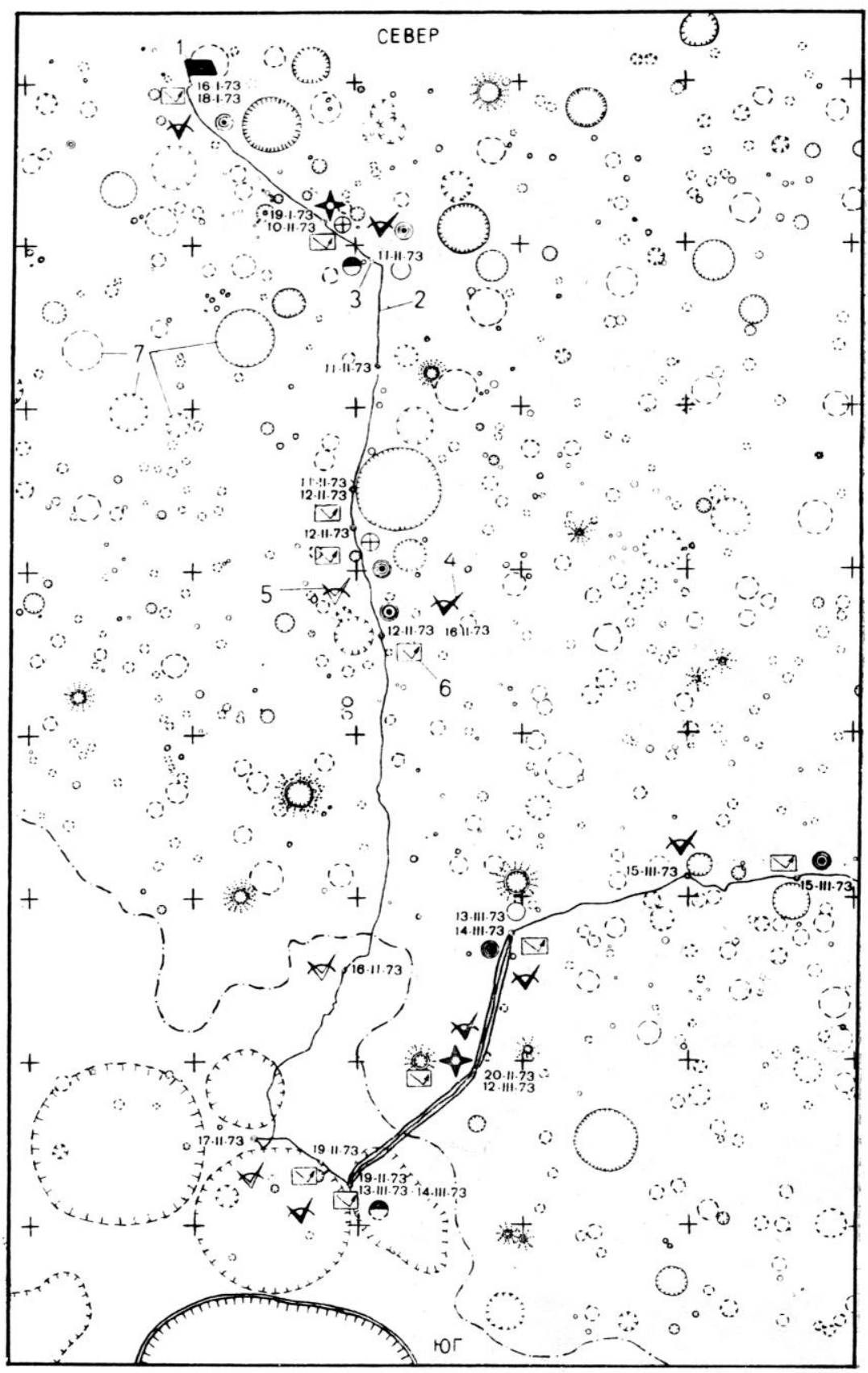




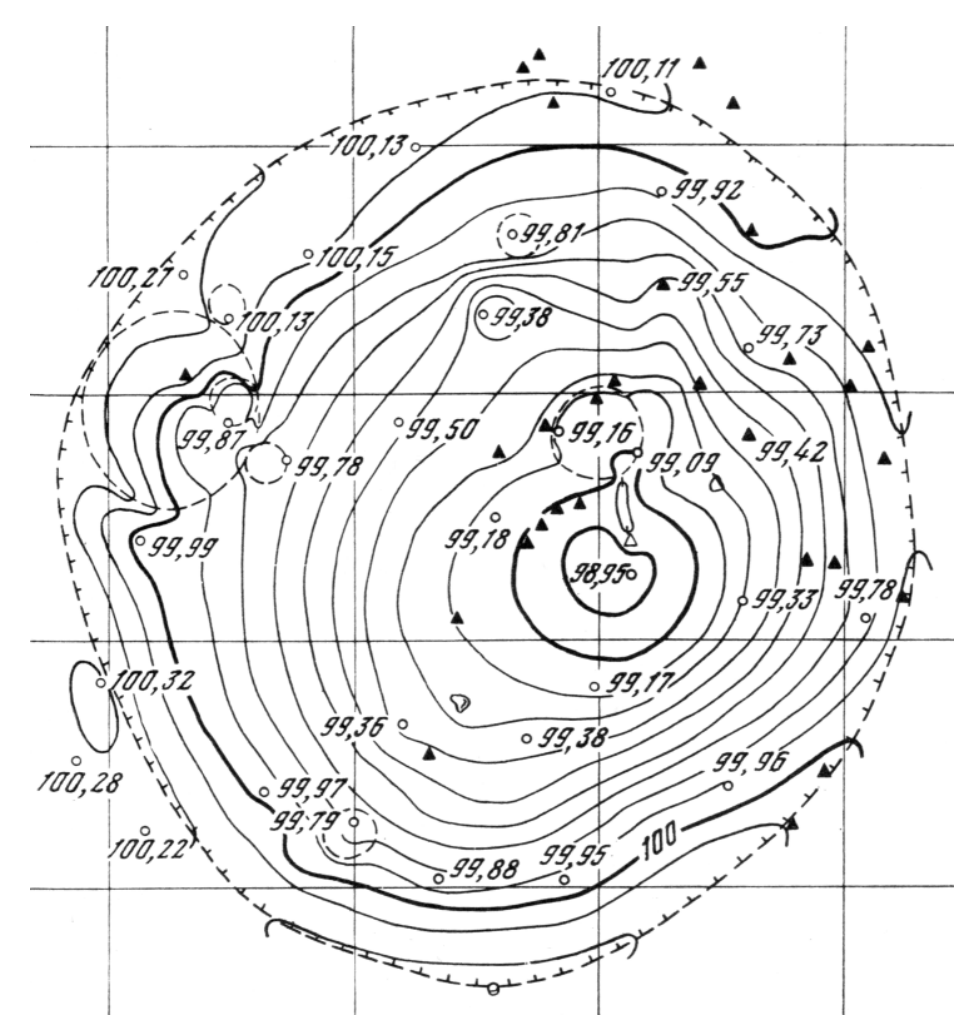

b)

Figure 6. Detailed maps of the Lunokhod-2 study area (Rodionov et al., 1973): a) topographic map on southwest part with "triple traverse", where the rover moved three times along the same traverse (original scale 1: 50,000); b) relief map of one of the small craters (original scale 1:

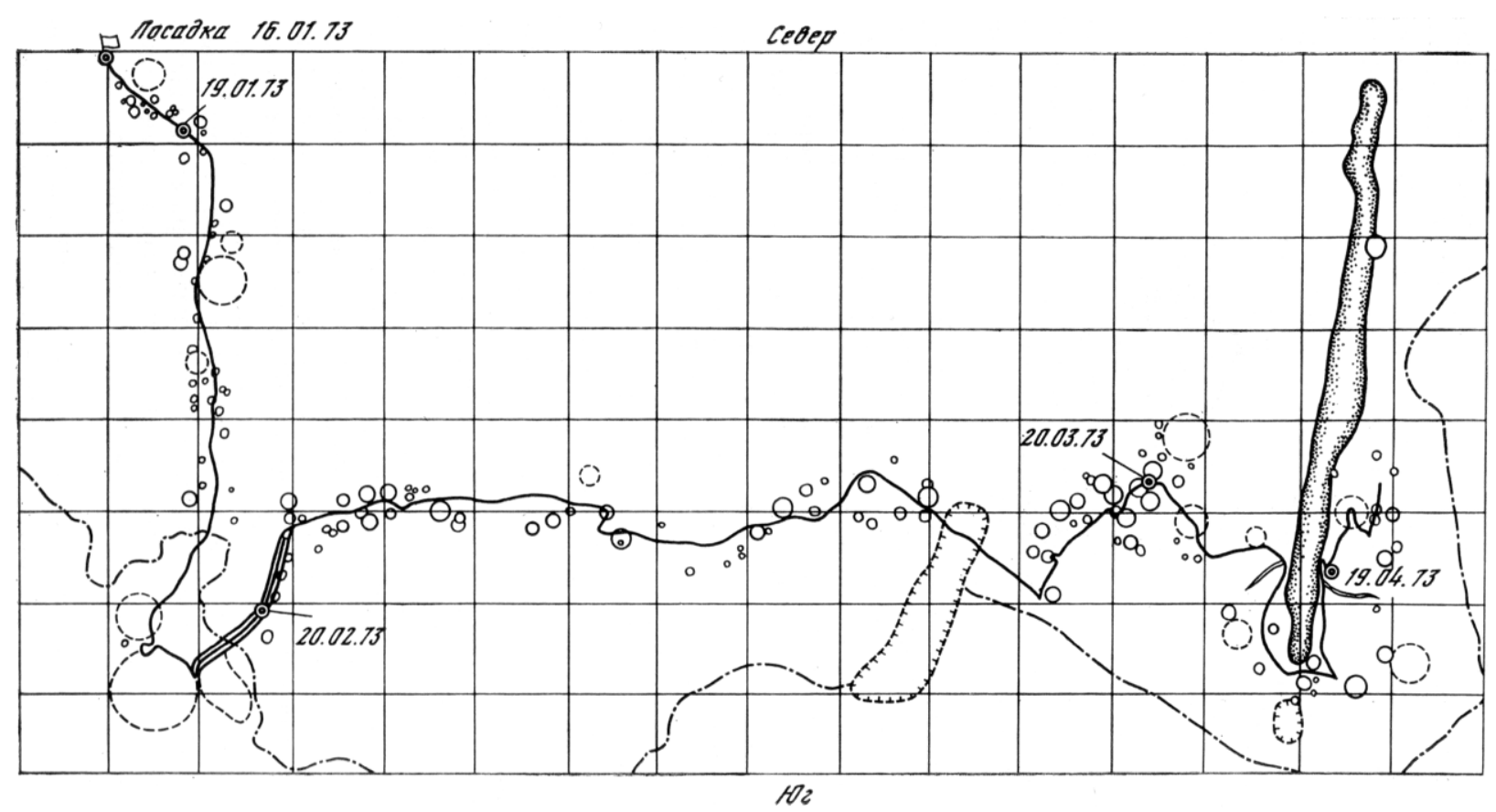

Figure 7. A topographic sketch map of Lunokhod-2 route (Kemurdzhian et al., 1978)

The first geologic map (Fig. 8a) based on results of a geomorphologic study of the Lunokhod-2 area (Florensky et al., 1974), as well as the geomorphologic sketch map (Fig.8b) derived from analyses of Le Monnier crater (Florensky et al., 1976; see also recent geologic review in Abdrakhimov, 2009) were compiled on the basis of the Lunokhod-2 route map. 


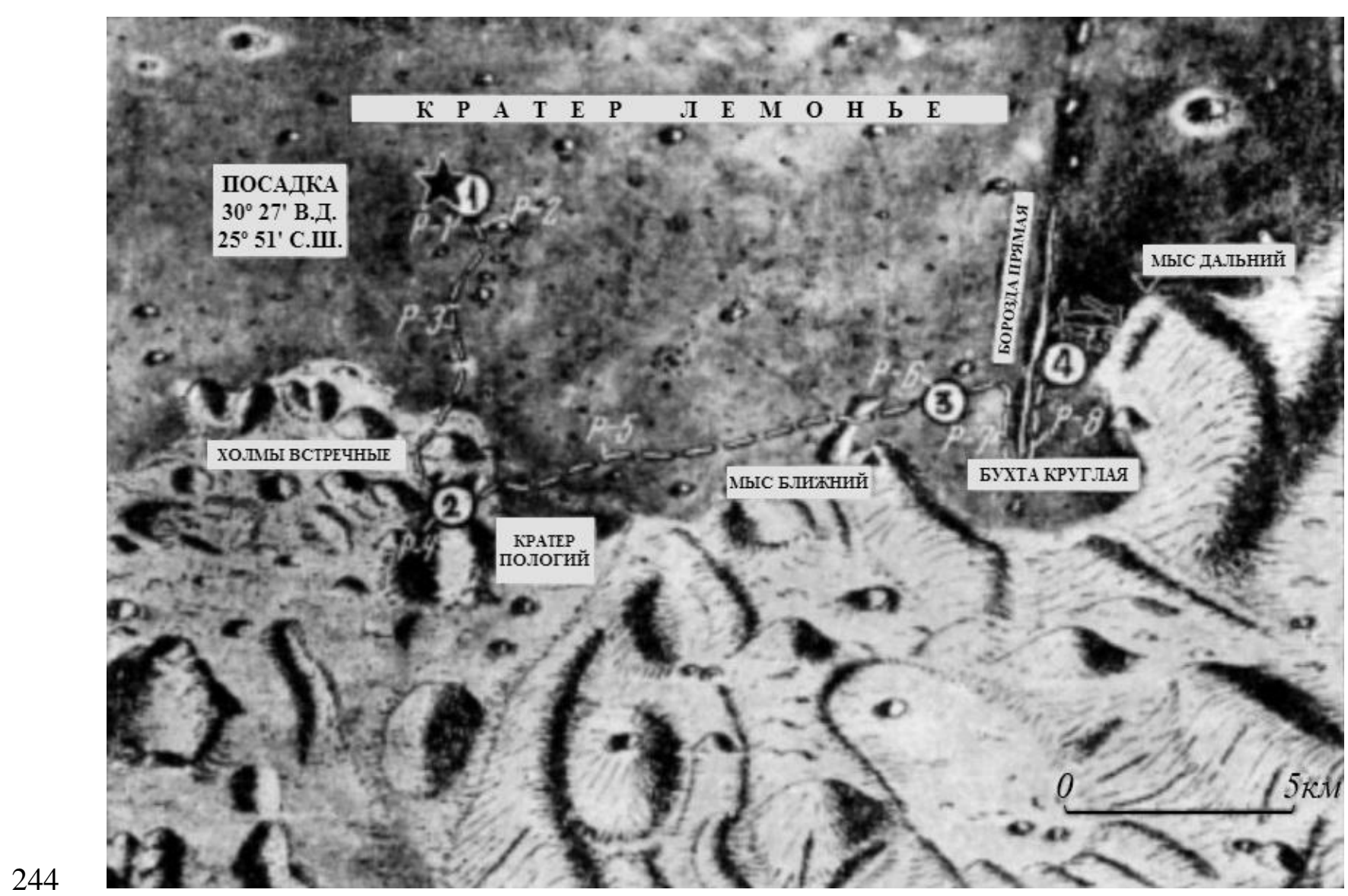

Figure 8a. Historic geologic map of Lunokhod-2 region, compiled by G.A. Burba. When first published (Florenskiy et al., 1974), unofficial names were used for lunar objects in the study area (here in Russian; for English names see Fig. 8b) 

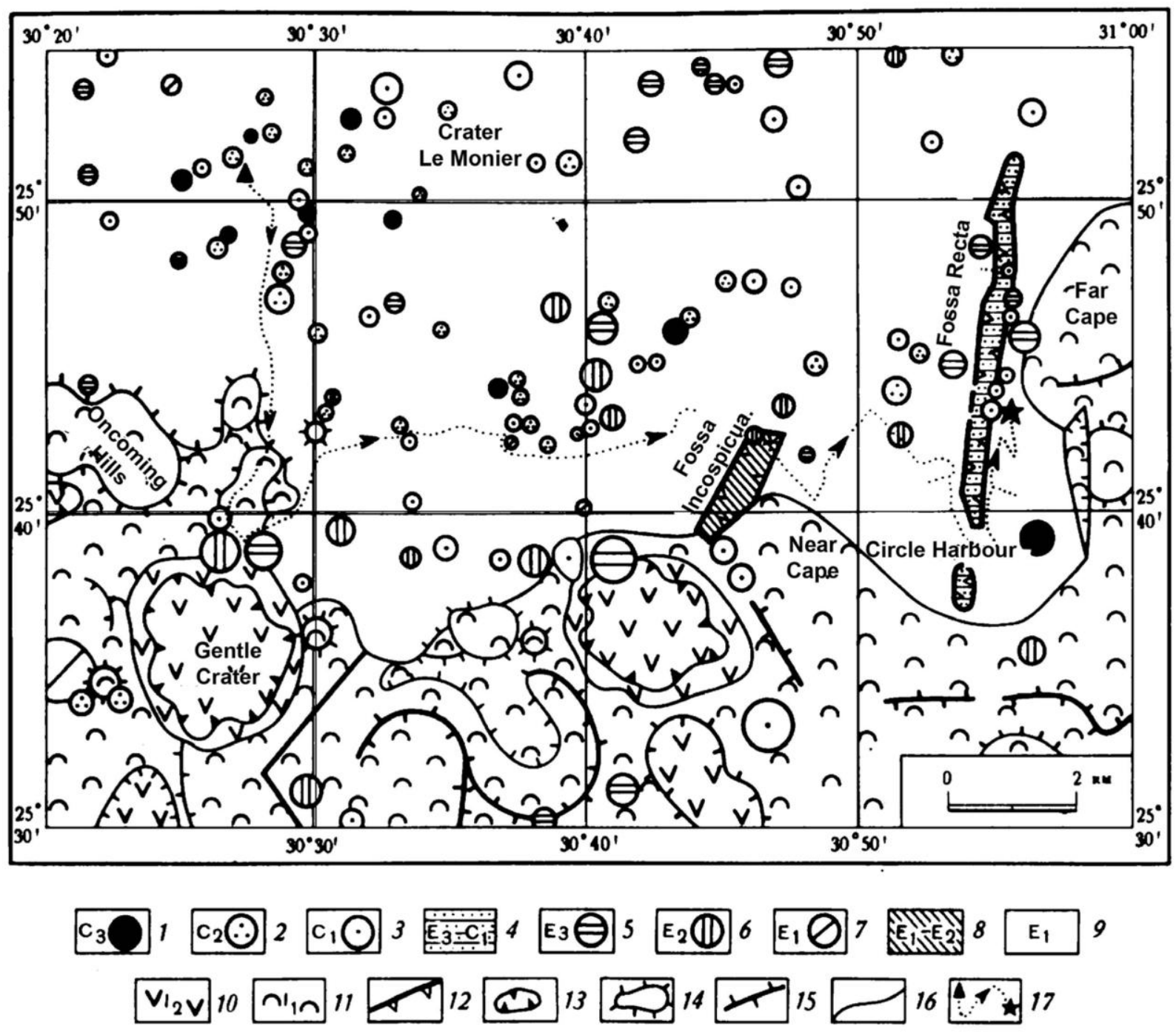

Figure 8b. Geomorphologic sketch map of Lunokhod-2 exploration area (Florensky et al., 1976): 1-3 - Late, Middle and Early Copernican craters; 4 -Fossa Recta; 5-7 - Late, Middle and Early Eratosthenian craters; 8 -Fossa Incospicua; 9 - Le Monnier lava-flooded crater floor; 10 - Late Imbrian craters; 11 - Le Monnier crater rim; 12 - tectonic scarps; 13 - large crater rims; 14 - hill slopes; 15 - ridges; 16 - geomorphologic boundaries; 17 - Lunokhod 2 route

More recently, the Lunokhod-2 study area was investigated using Clementine UV-VIS images with 100-m resolutions (Stooke, 2007) and NAC images (Abdrakhimov et al., 2011).

\section{LRO Data image processing \\ 3.1 LRO Mission}

The Lunar Reconnaissance Orbiter (LRO) was launched on June 18, 2009. After commissioning, LRO moved in a nearly circular, $50 \mathrm{~km}$, polar orbit during its first year of operation (Vondrak et al., 2010), but this orbit was changed to a slightly elliptical orbit for lowperiapsis passes and higher-resolution imaging, from approximately $21 \mathrm{~km}$ above the mean surface. With its extended science mission beginning in December 2011, LRO transferred to an elliptical (40 x 200 km) energy-saving "frozen orbit” (see also Haase et al., 2011).

\subsection{Camera and Images}

The LROC WAC obtains images at moderate resolution (100 and $400 \mathrm{~m}$ pixel scale) at ultraviolet and visible (321 to $689 \mathrm{~nm}$ ) seven-color, whereas the two identical NACs provide high-resolution $(0.5 \mathrm{~m} /$ pixel from $50 \mathrm{~km}$ altitude) monochrome images (Robinson et al., 2010). The NAC images are 5000 pixels wide and typically 52,224 lines long. Using adjacent orbits and 
with spacecraft tilt, the NAC regularly acquires overlapping stereo pairs ideally suited to produce high-resolution DEMs, and geometrically accurate orthoimages (Oberst et al., 2010; Scholten et al., 2012).

The Lunokhod-2 area as well as other lunar landing sites, such as Apollo 17 (Haase et al., 2011) and Luna-17 (Karachevtseva et al., 2013) are LROC priority targets, the Luna-21 area has been imaged many times with varying pixel scales, viewing, and illumination conditions (Table $1)$.

\subsection{Stereo image processing}

For the DEM and orthoimage production based on photogrammetric techniques, we used 59 NAC images (http://wms.lroc.asu.edu/lroc) of the study area (Table 1). Pre-processing was conducted by means of special developed software (Zubarev et al., 2016) using preliminary exterior orientation parameters (coordinate position of LROC NAC cameras) (Mazarico et al., 2012), provided by Spacecraft Position Kernels (SPKs) taken from SPICE (http://naif.jpl.nasa.gov/naif/data.html) at the selected time. Using this same software all images were converted from PDS-format (*.img) to an internal format of the digital photogrammetry system PHOTOMOD (Adrov et al., 1995).

In the next step, 342 tie-points, covering all images (Table 1), were measured based on semi-automatized correlation method in PHOTOMOD version 5.3 (http://www.racurs.ru/?page=634). The average number of measurements for each tie-point, using various images, is 10 and the maximum is 18 . A least-squares bundle block adjustment was carried out, following which the improved position and orientation of the NAC images. The PHOTOMOD implementation of the block adjustment is based on the RPC model (Grodecki and Dial, 2003), which is characterized by an effectively reduced number of adjustment parameters (6 per image) providing a numerically stable solution. Considering the average pixel size of 1.0 $\mathrm{m}$, the coordinate accuracy on the lunar surface (RMS errors) were estimated as RMSx $= \pm 1.8 \mathrm{~m}$, RMSy $= \pm 3.9 \mathrm{~m}, \mathrm{RMSz}= \pm 4.3 \mathrm{~m}$.

The NAC typically obtains nadir images (consequently, emission angles are close to $1^{\circ}$, see Table 1), however, the spacecraft was occasionally tilted to obtain stereo images for targets of interest (resulting in emission angles of $>10$ degree) with convergence more than $5^{\circ}$. As images were obtained at different times of the day, illumination varies accordingly, so only 5 stereo pairs obtained under similar lighting conditions, as recommended for automated 3-D terrain processing (Becker et al., 2015), were chosen for creating the DEM covering the entire Luna-21 activity area; for each of 5 pairs the difference in solar azimuth and solar incidence angle is not more than $15^{\circ}$ for image correlation in a single pair.

We produced the DEM with resolution $2.5 \mathrm{~m} /$ pixel (Fig. 9) based on algorithms of automatic relief generation using a semi-global approach (Hirschmüller, 2005), which uses the iterative-deformation method implemented in PHOTOMOD software (Sechin, 2014). This method takes into account the result of transformation (deformation) of multiple overlapping elevation models produced in several iterations. In the first iteration a preliminary elevation model $\mathrm{H}_{0}$ (level 0) is used, interpolated from the measured tie-points. In the next steps transformations are made with various elevation models $H_{ \pm i}$ looking for maximal coefficient of correlation between overlapping models during $i$-iterations at one level.

Finally, data with favorable conditions (Table 1) - both with high resolution and similar illumination (with small discrepancy in solar azimuth and incidence angle from images taken from sequential orbits; in our case time difference not more than 4 hours) - were selected for mosaicking (Fig. 10) for further analysis and mapping.

Table 1. Images used for DEM processing and mosaicking

\begin{tabular}{|l|l|c|c|c|c|c|}
\hline $\begin{array}{c}\text { Number } \\
\text { of } \\
\text { images }\end{array}$ & Image IDs & Date and time & $\begin{array}{c}\text { Pixel scale, } \\
\mathbf{m}\end{array}$ & $\begin{array}{c}\text { Emission } \\
\text { angle, } \\
\text { o }\end{array}$ & $\begin{array}{c}\text { Solar } \\
\text { azimuth, } \\
\text { o }\end{array}$ & $\begin{array}{c}\text { Incidence } \\
\text { angle, } \\
\text { o }\end{array}$ \\
\hline 1. & M101971016LE & $11.07 .200917: 02$ & 1.5 & 14.58 & 183.64 & 82.99 \\
\hline
\end{tabular}




\begin{tabular}{|c|c|c|c|c|c|c|}
\hline 2. & M101971016RE & 11.07.2009 17:02 & 1.5 & 17.35 & 183.22 & 83.23 \\
\hline 3. & M106669064LE & 04.09.2009 02:04 & 1.67 & 17.64 & 228.29 & 37.54 \\
\hline 4. & M106669064RE & 04.09.2009 02:04 & 1.67 & 14.87 & 226.38 & 37.75 \\
\hline 5. & M106683404RE & 04.09.2009 06:02 & 1.5 & 1.21 & 219.92 & 38.79 \\
\hline 6. & M109039075LE & 01.10 .2009 12:23 & 0.56 & 15.00 & 82.67 & 27.42 \\
\hline 7. & M109039075RE & 01.10 .2009 12:23 & 0.56 & 12.23 & 83.06 & 27.41 \\
\hline 8. & M119646179LE & 01.02.2010 06:48 & 0.56 & 3.74 & 196.34 & 59.43 \\
\hline 9. & M119646179RE & 01.02.2010 06:48 & 0.56 & 0.92 & 195.52 & 59.50 \\
\hline 10. & M122007650LE & 28.02.2010 14:46 & 0.56 & 11.40 & 220.83 & 36.53 \\
\hline 11. & M122007650RE & $28.02 .201014: 46$ & 0.56 & 8.64 & 219.53 & 36.59 \\
\hline 12. & M129086218LE & 21.05.2010 13:02 & 0.56 & 1.64 & 162.36 & 56.23 \\
\hline 13. & M129086218RE & 21.05.2010 13:02 & 0.56 & 1.13 & 162.51 & 56.30 \\
\hline 14. & M131440712LE & 17.06.2010 19:04 & 0.56 & 18.78 & 176.39 & 80.26 \\
\hline 15. & M131440712RE & 17.06.2010 19:04 & 0.56 & 21.60 & 176.11 & 80.34 \\
\hline 16. & M139707174LE & 21.09.2010 11:18 & 0.56 & 4.57 & 249.57 & 28.40 \\
\hline 17. & M139707174RE & 21.09.2010 11:18 & 0.56 & 7.50 & 248.53 & 28.42 \\
\hline 18. & M146783727LE & 12.12.2010 09:01 & 0.9 & 1.68 & 172.21 & 75.46 \\
\hline 19. & M146783727RE & 12.12.2010 09:01 & 0.92 & 1.13 & 172.20 & 75.52 \\
\hline 20. & M165645602LE & 18.07.2011 16:25 & 0.5 & 0.68 & 190.95 & 70.12 \\
\hline 21. & M165645602RE & 18.07.2011 16:25 & 0.56 & 1.13 & 190.27 & 70.18 \\
\hline 22. & M168000478LE & $14.08 .201122: 33$ & 0.5 & 27.13 & 218.90 & 47.61 \\
\hline 23. & M168000478RE & $14.08 .201122: 33$ & 0.5 & 24.36 & 216.81 & 47.65 \\
\hline 24. & M172717196LE & 08.10.2011 12:45 & 0.57 & 0.89 & 116.66 & 30.03 \\
\hline 25. & M172717196RE & 08.10.2011 12:45 & 0.57 & 3.66 & 117.02 & 30.05 \\
\hline 26. & M175070494LE & 04.11.2011 18:27 & 0.57 & 25.73 & 154.18 & 47.90 \\
\hline 27. & M175070494RE & 04.11.2011 18:27 & 0.57 & 28.50 & 153.82 & 47.94 \\
\hline 28. & M177426582RE & 02.12.2011 00:55 & 0.57 & 23.63 & 171.04 & 71.52 \\
\hline 29. & M177433351LE & 02.12.2011 02:48 & 0.57 & 17.53 & 280.48 & 70.67 \\
\hline 30. & M177433351RE & 02.12.2011 02:48 & 0.57 & 14.76 & 166.34 & 70.73 \\
\hline 31. & M180966502LE & $12.01 .201200: 13$ & 1.52 & 1.78 & 190.57 & 70.57 \\
\hline 32. & M183325364RE & 08.02.2012 07:28 & 1.51 & 1.20 & 206.51 & 46.39 \\
\hline 33. & M185684246LE & 06.03.2012 14:42 & 1.4 & 1.78 & 243.23 & 27.22 \\
\hline 34. & M188035994LE & 02.04.2012 19:58 & 1.49 & 6.19 & 125.17 & 28.92 \\
\hline 35. & M188035994RE & 02.04.2012 19:58 & 1.49 & 9.17 & 125.58 & 29.04 \\
\hline 36. & M188043142LE & 02.04.2012 21:57 & 1.49 & 1.78 & 122.85 & 28.65 \\
\hline 37. & M1105709502LE* & $24.10 .201209: 17$ & 1.36 & 16.27 & 150.69 & 45.29 \\
\hline 38. & M1105709502RE* & 24.10.2012 09:17 & 1.36 & 19.04 & 150.63 & 45.49 \\
\hline 39. & M1105723789RE* & 24.10.2012 13:15 & 1.36 & 4.44 & 146.08 & 43.95 \\
\hline 40. & M1105723789LE* & 24.10.2012 13:15 & 1.36 & 7.21 & 145.43 & 43.78 \\
\hline 41. & M1108074725RE & 20.11.2012 18:17 & 1.48 & 1.20 & 166.77 & 67.48 \\
\hline 42. & M1108074725LE & 20.11.2012 18:17 & 1.48 & 1.77 & 166.60 & 67.27 \\
\hline 43. & M1113965174RE* & 27.01.2013 22:32 & 1.37 & 6.51 & 205.18 & 48.81 \\
\hline 44. & M1113965174LE* & $27.01 .201322: 32$ & 1.37 & 9.27 & 206.37 & 48.62 \\
\hline 45. & M1113986482RE* & 28.01.2013 04:27 & 1.37 & 29.72 & 200.53 & 51.28 \\
\hline 46. & M1113986482LE* & 28.01.2013 04:27 & 1.37 & 26.95 & 200.94 & 51.03 \\
\hline 47. & M1118681776RE & $23.03 .2013 \quad 12: 42$ & 1.26 & 1.13 & 117.53 & 27.11 \\
\hline 48. & M1118681776LE & 23.03.2013 12:42 & 1.26 & 1.64 & 116.90 & 27.02 \\
\hline
\end{tabular}




\begin{tabular}{|l|l|l|l|l|l|l|} 
49. & M1123399010LE & $17.05 .201303: 03$ & 1.4 & 1.64 & 170.50 & 68.45 \\
\hline 50. & M1126921794RE** & $26.06 .201321: 36$ & 1.39 & 3.84 & 187.12 & 75.25 \\
\hline 51. & M1126921794LE** & $26.06 .201321: 36$ & 1.39 & 6.61 & 187.78 & 75.04 \\
\hline 52. & M1126928906LE** & $26.06 .201323: 34$ & 1.39 & 1.36 & 186.92 & 75.57 \\
\hline 53. & M1126928906RE** & $26.06 .201323: 34$ & 1.39 & 4.13 & 186.36 & 75.77 \\
\hline 54. & M1126936017LE** & $2013-06-2701: 32$ & 1.30 & 9.79 & 186.37 & 76.08 \\
\hline 55. & M1126936017RE** & $2013-06-2701: 32$ & 1.30 & 12.74 & 185.87 & 76.29 \\
\hline 56. & M1129282798LE & $24.07 .201305: 26$ & 1.39 & 1.64 & 202.72 & 52.45 \\
\hline 57. & M1129282798RE & $24.07 .201305: 26$ & 1.39 & 1.13 & 201.77 & 52.64 \\
\hline 58. & M1131636702LE & $20.08 .201311: 17$ & 1.28 & 1.64 & 230.85 & 33.17 \\
\hline 59. & M1131636702RE* & $20.08 .201311: 17$ & 1.28 & 1.13 & 229.59 & 33.30 \\
\hline
\end{tabular}

* images used for DEM production (Table 2)

** images used for mosaicking (Fig.10)

Table 2. Parameters of LROC NAC stereo pairs used for DEM production

\begin{tabular}{|c|c|c|c|}
\hline $\begin{array}{c}\text { Number } \\
\text { of pairs }\end{array}$ & Image IDs & $\begin{array}{c}\text { Angle of } \\
\text { convergence, } \\
\text { o }\end{array}$ & $\begin{array}{c}\text { Nominal } \\
\text { elevation } \\
\text { accuracy, m }\end{array}$ \\
\hline 1 & M1131636702RE - M1113986482RE & 32.2 & 1.8 \\
\hline 2 & M1113986482RE - M1113965174RE* & 38.6 & 1.7 \\
\hline 3 & M1105709502LE - M1105723789LE & 25.5 & 2.9 \\
\hline 4 & M1105709502RE - M1105723789RE & 25.2 & 2.9 \\
\hline 5 & M1113986482LE - M1113965174LE & 39.3 & 1.8 \\
\hline
\end{tabular}

326 * stereo pair used for measurements of the Lunokhod-2 final position

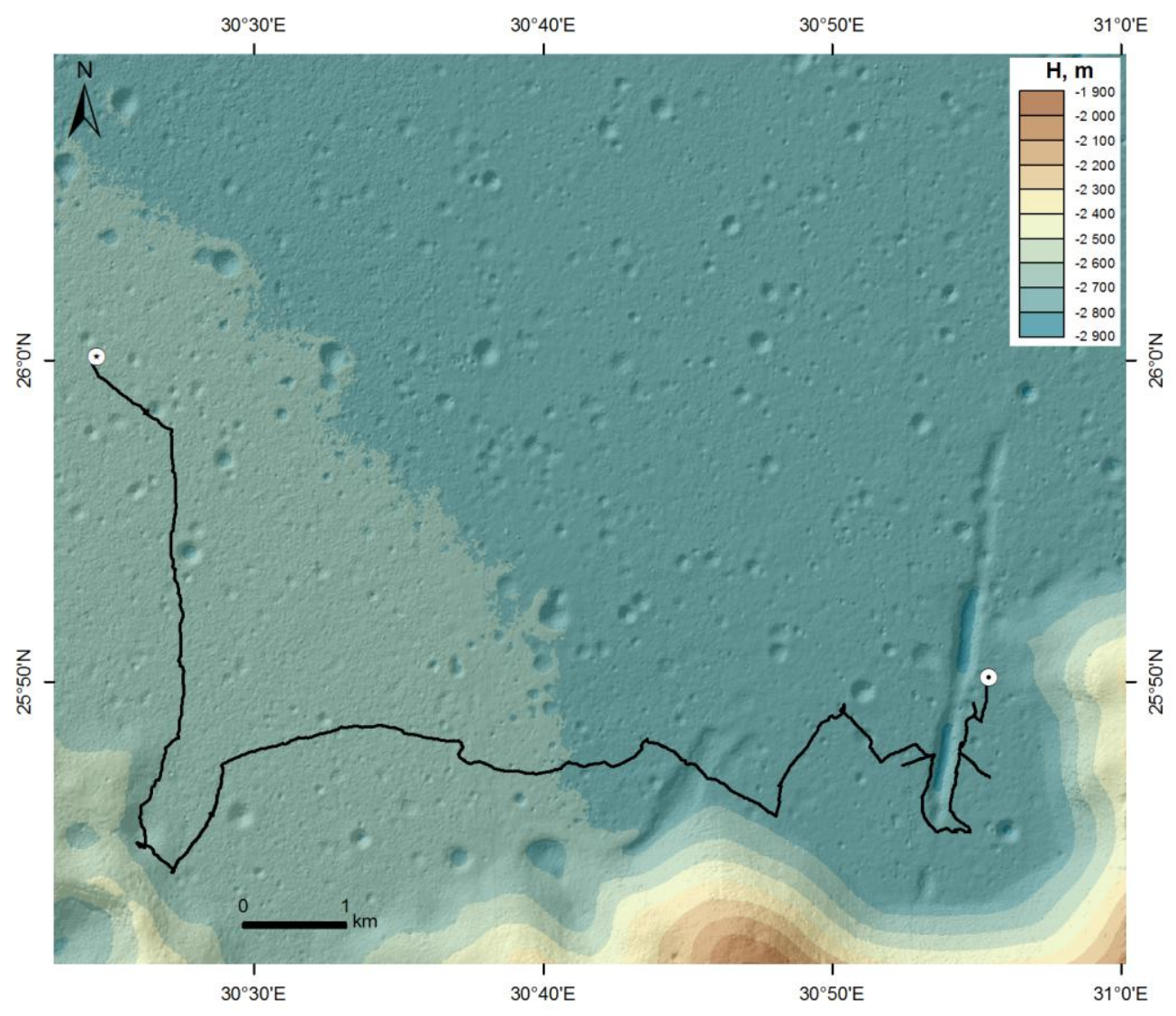


Figure 9. DEM for Lunokhod-2 area with resolution $2.5 \mathrm{~m} /$ pixel produced from

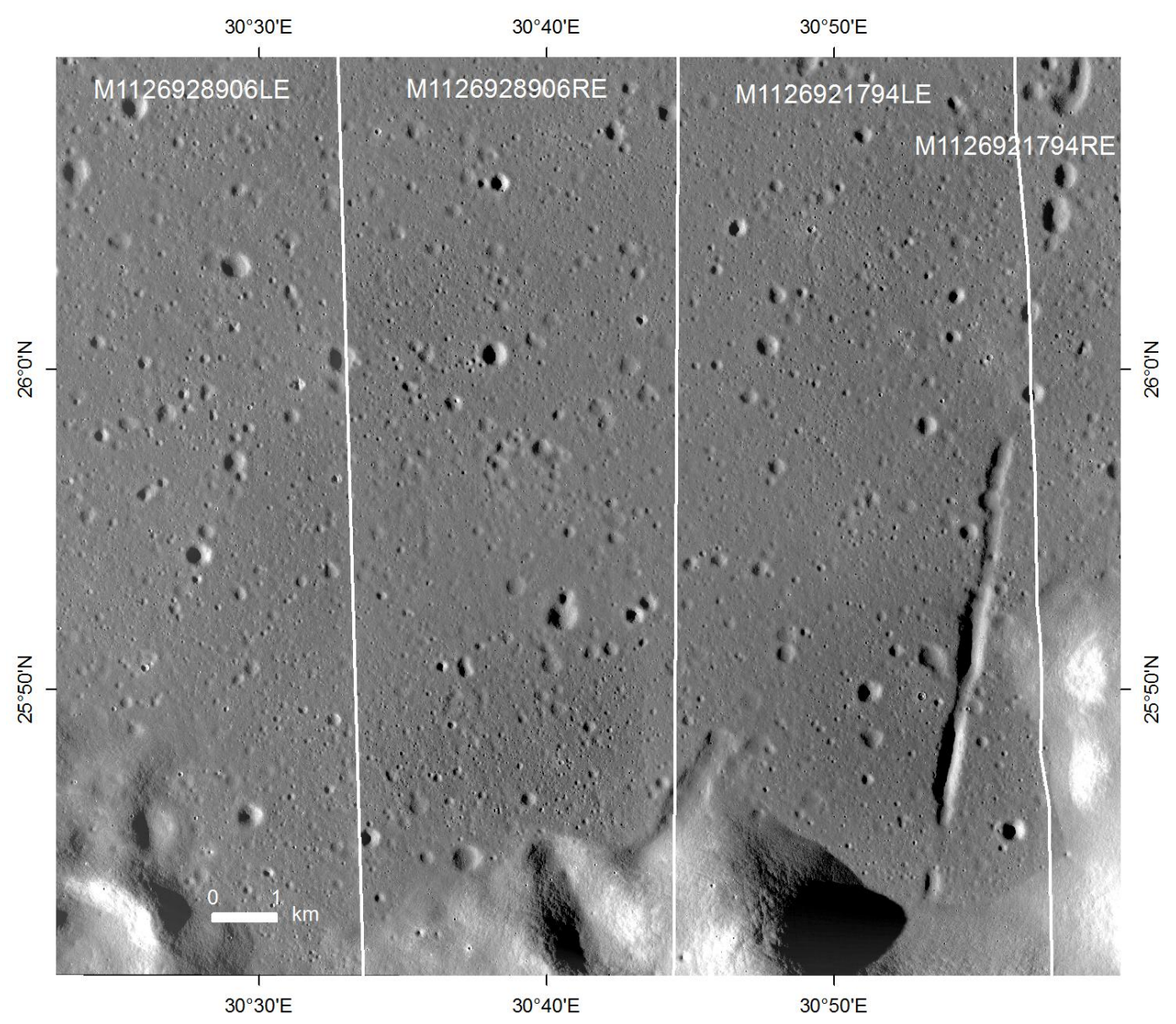

a) 


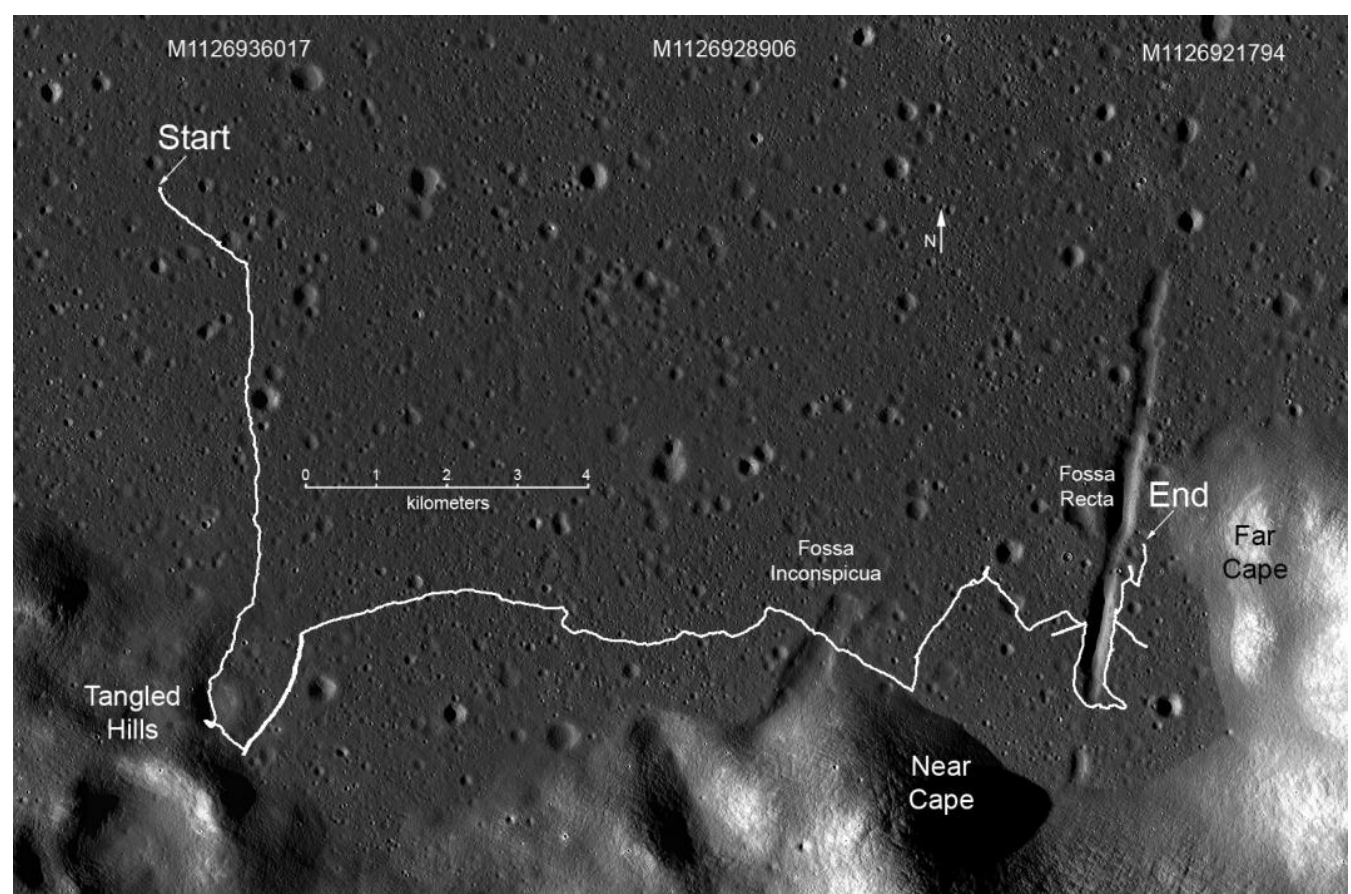

b)

Figure 10. a) Orthomosaic for the Lunokhod-2 area with resolution $2.5 \mathrm{~m} /$ pixel produced from NAC images and DEM using PHOTOMOD software; b) NAC image mosaic with annotation showing the traverse route as traced on individual images.

Table 3. Comparison of stereo measurements (this study) and Lunar Laser Ranging (Williams et al., 2013) for final position of Lunokhod-2

\begin{tabular}{|c|c|c|c|c|c|c|}
\hline & $\mathbf{X}, \mathbf{m}$ & $\mathbf{Y}, \mathbf{m}$ & $\mathbf{Z}, \mathbf{m}$ & $\begin{array}{c}\text { Longitude, } \\
\circ\end{array}$ & $\begin{array}{c}\text { Latitude, } \\
\circ\end{array}$ & $\begin{array}{c}\text { Elevation, } \\
\mathbf{m}\end{array}$ \\
\hline $\begin{array}{l}\text { L-2 } \\
\text { coordinates } \\
\text { (LLR) }\end{array}$ & 1339388.601 & 802309.554 & 755849.750 & 30.9221056 & 25.8323282 & -2761.338 \\
\hline $\begin{array}{l}\text { L-2 } \\
\text { coordinates } \\
\text { (LROC } \\
\text { NAC } \\
\text { DEM) } \\
\end{array}$ & 1339294.5 & 802303.9 & 755918.3 & 30.92371 & 25.83558 & -2807.1 \\
\hline Differences & 94.1 & 5.6 & -68.6 & -0.00160 & -0.00325 & 45.8 \\
\hline
\end{tabular}

Comparison of the Lunokhod-2 final position coordinates obtained in this study from stereo measurements (Table 3) with LLR data (Williams et al., 2013) as well with data derived from images with corrected SPKs (Wagner et al., 2014) indicates that the average discrepancy is $\sim 118 \mathrm{~m}$. To remove this systematic error we adjusted the DEM and the orthomosaic to LLR coordinates of the final position of Lunokhod-2 by shifting the latitude and longitude (assuming rotational offsets to be minimal). Using the transformed data as a basis for the spatial measurements, all coordinates of this paper are given in the LLR system (see Tables 6-7). The remaining errors of the coordinates are as follows: elevation accuracy is $\pm 3 \mathrm{~m}$ derived from maximal value of nominal elevation accuracy of the DEM (2.9 m, Table 2); RMS error of plane coordinates is $\pm 2 \mathrm{~m}$ derived from nominal resolution of images used for orthomosaicking $(1.4 \mathrm{~m}$, Table 1) and operator error (1 pixel).

\section{Study of Lunokhod-2 area 4.1 Traverse identification}


The Lunokhod-2 route was primarily west to east, (contrary to Lunokhod-1, which moved south to north), and Lunokhod-2 travelled a distance four times longer than Lunokhod-1. Hence, several sets of NAC images were required to cover the Lunokhod-2 study area. These images were acquired over several different LRO mission phases.

For track identification we used the highest-resolution NAC images, taken under complementary illumination conditions, as the visibility of the wheel tracks strongly depends on solar azimuth and incidence angle, similar to crater identification (Florensky et al., 1978; Basilevsky et al., 2012). In high sun illumination, the tracks are very difficult to identify (Fig. 11a), whereas with low Sun (big solar incidence angle), the tracks are clearly visible (Fig. 11b). For the analysis of the traverse we used an orthomosaic (Fig 11c) that includes images with best visibility of the track $(81 \%$ of the mosaic is covered by images with pixel scales of $\sim 0.5 \mathrm{~m}$ and $19 \%$, about $1.0 \mathrm{~m})$.

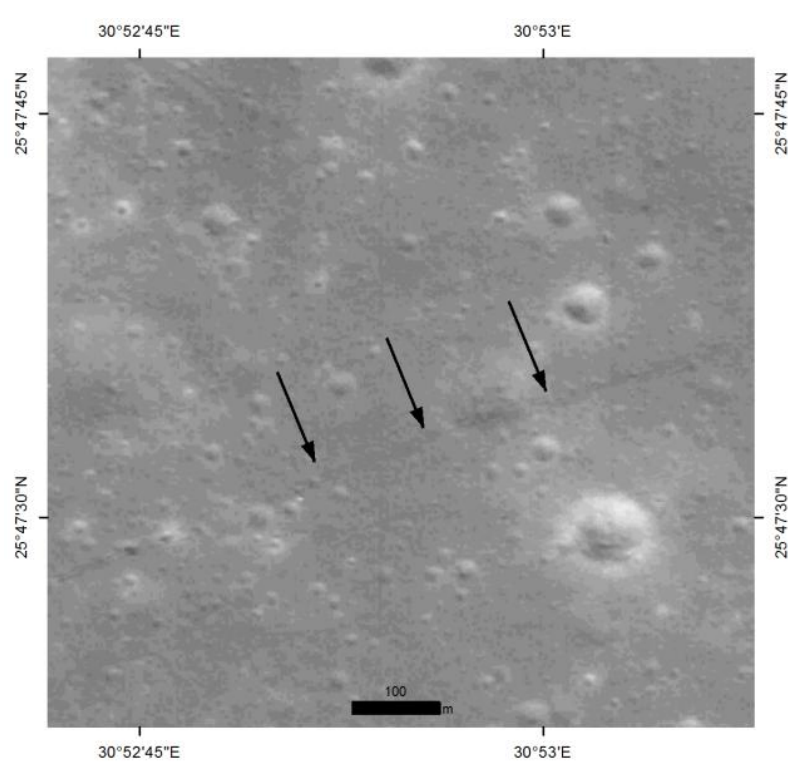

a)

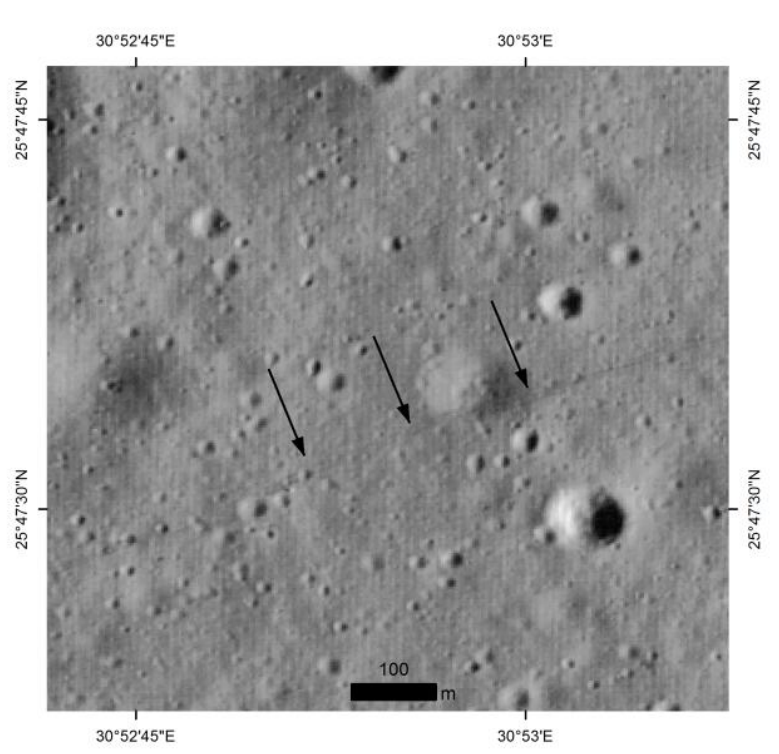

b)

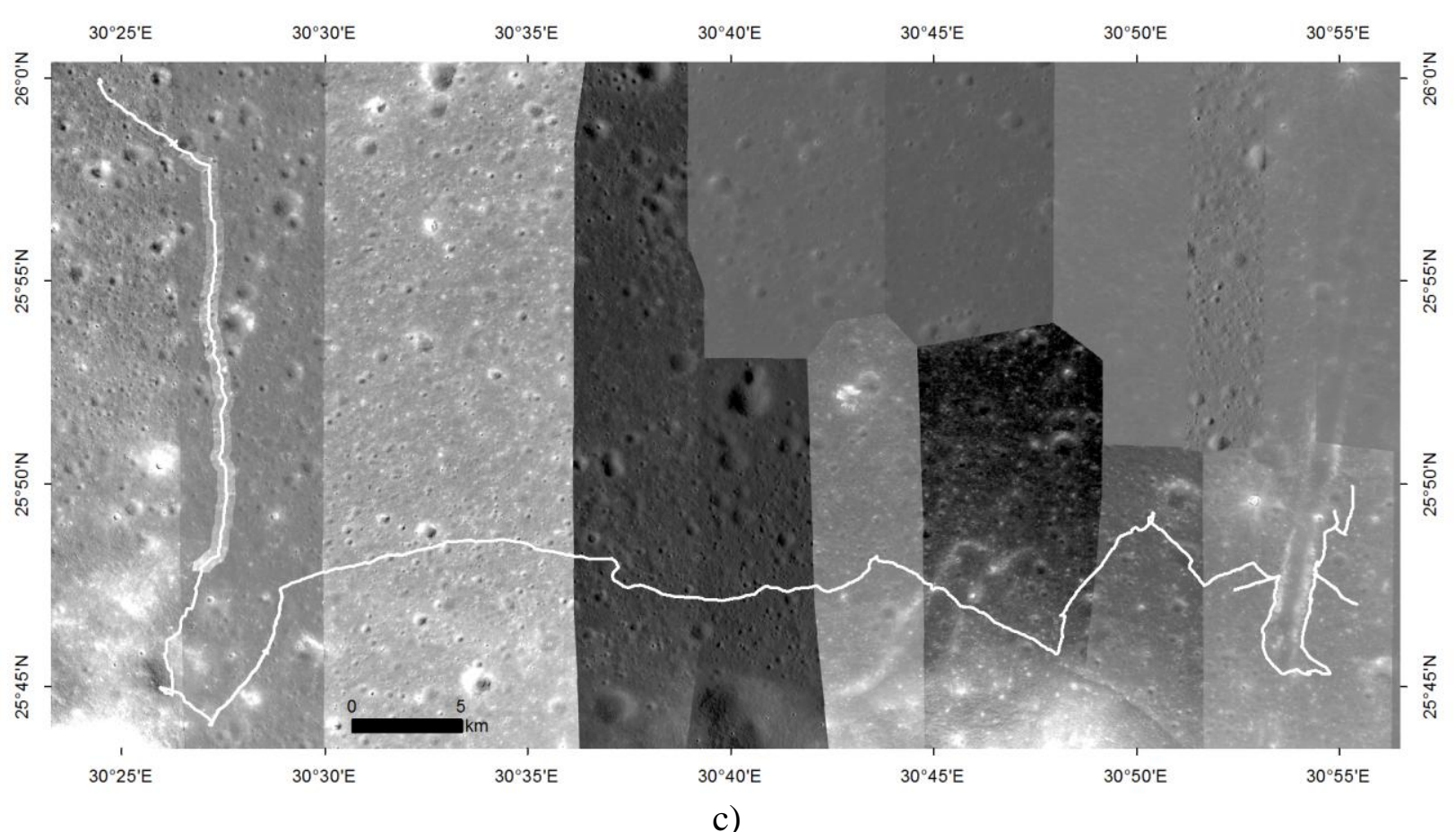

Figure 11. Lunokhod-2 route on various LROC NAC images with different illumination conditions: a) poor visibility of traverse with high Sun (image M109039075LE, solar incidence angle $27^{\circ}$ ); b) good visibility of traverse with low Sun (image M177433351RE, solar incidence 
angle $71^{\circ}$ ); c) orthomosaic with high quality visible track, produced to identify the route (equidistant cylindrical projection with center at study area - main meridian $30^{\circ} 40^{\prime}$, standard parallel $25^{\circ} 50^{\prime}-$ is used for all maps in the paper)

The Lunokhod-2 traverse was manually detected and digitized in ArcGIS 10.3 (http://www.esri.com/) and in ISIS3 using the program Qview (Anderson et al., 2004). To obtain the most accurate positions for the traverse we used two different methods and software implementations: 1) 3D-stereo measurements in original stereo images, using PHOTOMOD, and 2) 3D-measurements in ArcGIS using the DEM.

Table 4. Lunokhod-2 route measurements

\begin{tabular}{|c|c|c|c|c|}
\hline $\begin{array}{l}\text { Lunar } \\
\text { day }\end{array}$ & Date & Description & $\begin{array}{c}\text { New distances } \\
\text { measured in } \\
\text { GIS } \\
\text { (this study) }\end{array}$ & $\begin{array}{c}\text { Distances } \\
\text { measured by } \\
\text { Lunokhod-2 9-th } \\
\text { wheels during } \\
\text { Luna-21 mission } \\
\text { (Dovgan, 2015) }\end{array}$ \\
\hline & & & \multicolumn{2}{|c|}{ Distance, $\mathrm{m}$} \\
\hline 1 & $16.01-24.01 .1973$ & $\begin{array}{l}\text { Lunokhod-2 moved to the } \\
\text { southeast. }\end{array}$ & 1299 & 1148 \\
\hline 2 & $08.02-22.02 .1973$ & $\begin{array}{l}\text { Lunokhod-2 moved to the } \\
\text { south. Study of crater with } \\
\text { a diameter of } 720 \mathrm{~m} \text {. Turn } \\
\text { to east. }\end{array}$ & 10034 & 9919 \\
\hline 3 & $09.03-21.03 .1973$ & $\begin{array}{l}\text { Lunokhod-2 moved east. } \\
\text { Crossed the depression } \\
\text { width } 400 \mathrm{~m} \text {, depth } 27 \mathrm{~m} . \\
\text { Turned to the northeast. }\end{array}$ & 17622 & 16533 \\
\hline 4 & $08.04-22.04 .1973$ & $\begin{array}{l}\text { Lunokhod-2 moved to the } \\
\text { southeast - to southern tip } \\
\text { of Fossa Recta. Traversed } \\
\text { around Fossa Recta from } \\
\text { the south to the north. }\end{array}$ & 9136 & 8600 \\
\hline 5 & $08.05-10.05 .1973$ & $\begin{array}{l}\text { Lunokhod-2 moved to the } \\
\text { north along Fossa Recta }\end{array}$ & 1014 & 880 \\
\hline & & Total & $\sum 39105$ & $\sum 37080$ \\
\hline
\end{tabular}

395

396

397

398

399

400

401

402

403

404

405

406

407

Following identification of the traverse, the lengths of individual parts of the Lunokhod-2 traverse, from different lunar days, have been determined (Table 4). The total length of the traverse was measured as $39.1 \mathrm{~km}$ (average from both techniques), significantly longer $(\sim 2 \mathrm{~km})$ (Table 4) than the previously published result of $37 \mathrm{~km}$, which was based on the onboard odometer measurements (http://www.laspace.ru/rus/luna21.html).

The discrepancy between historic and modern distance measurements (Fig. 12) probably has multiple causes: 1) lost navigation equipment after landing; 2) accumulated errors along path; 3) mistakes based on odometer measurements (9th wheel); and 4) differences between two methods of measurements (odometer and digitizing tracks). Despite the differences, two old maps manually referenced to tracks digitized in GIS show a good correlation between various data, demonstrating the excellent navigation work that was done during the Luna-21 mission (Fig. 12). 

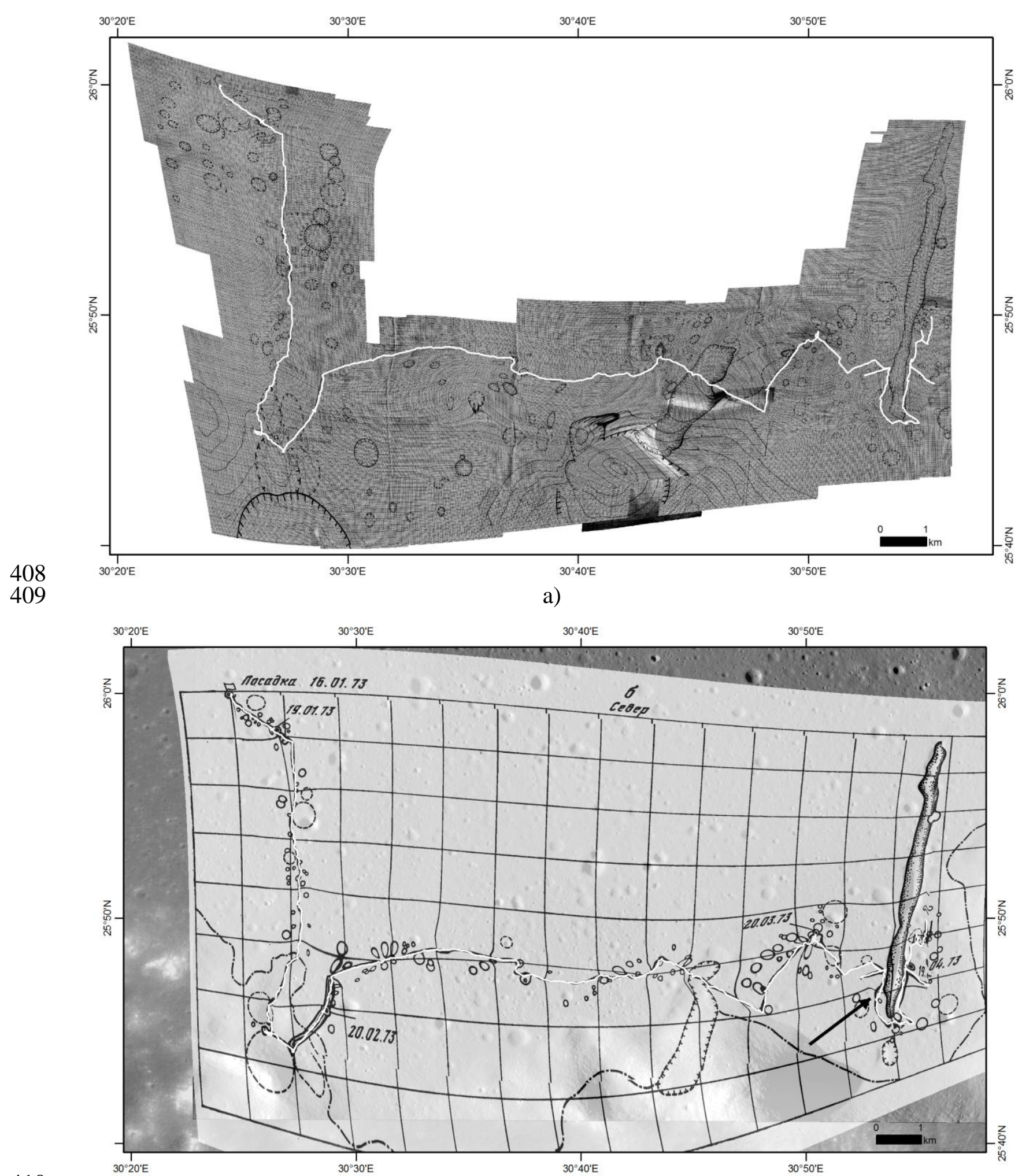

410

411

412

413

414

415

416

417

418

a)

b)

Figure 12. Differences between Lunokhod-2 route, digitized in GIS (white), and the route from transformed historic map (black): a) operative schema produced during Luna-21 mission; b) topographic schema, produced as result of analysis and mapping after mission (maximal discrepancy is about $80 \mathrm{~m}$ ).

\subsection{Morphometric analysis}

Based on the DEM and the digitized track, morphometric parameters of the Lunokhod-2 route were analyzed. We extracted a topographic profile (Fig. 13) and computed slopes along the traverse (Fig. 14). 
Height, $m$

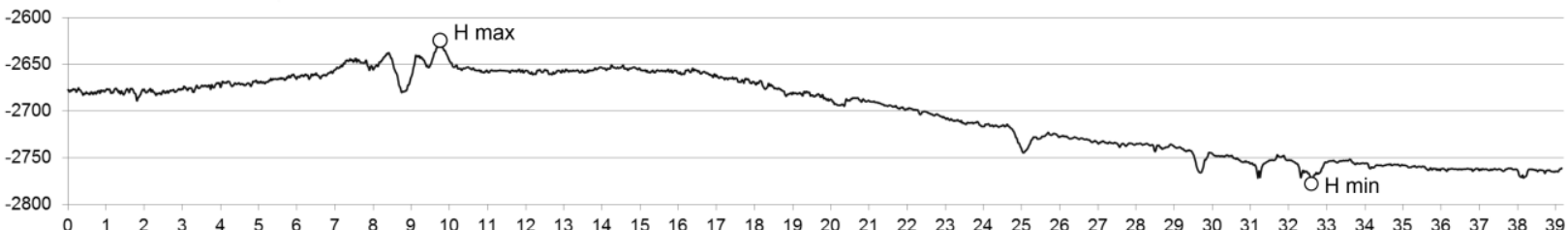

421

422

Distance, $\mathrm{km}$

a)

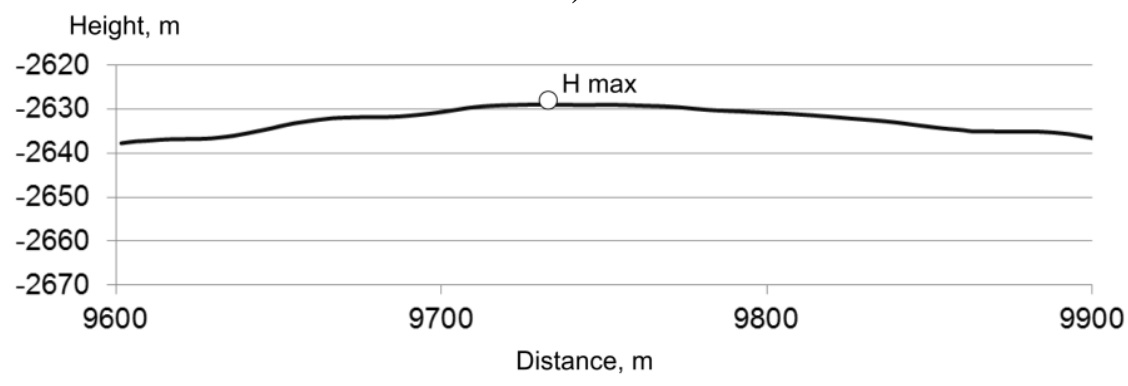

b)

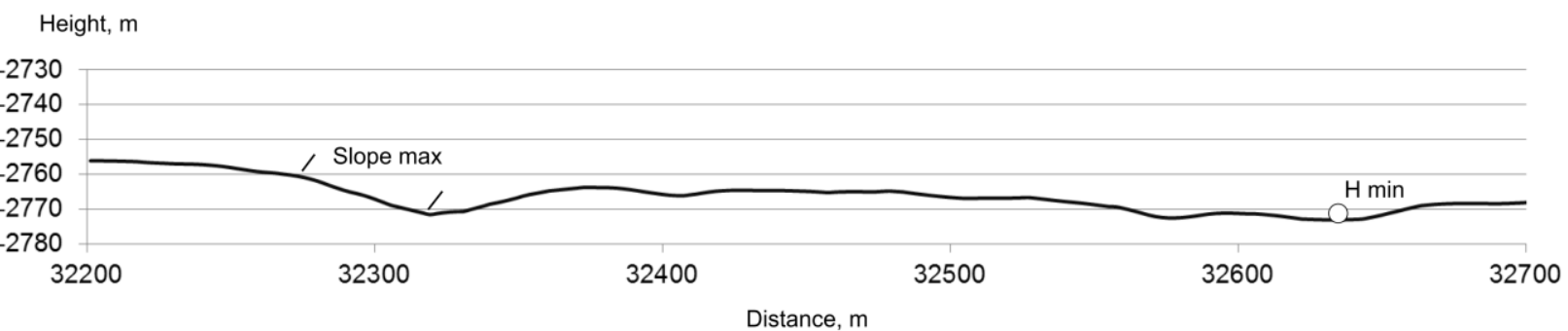

c)

Figure 13. Topographic profile of Lunokhod-2 route: a) elevations along the route (vertical exaggeration $=20$ ); ) portion of route with maximum elevation; c) portion of route (near Fossa Recta) with lowest elevation and the maximum slope.

The highest point of the traverse is $-2629 \mathrm{~m}$ (Fig. 13b), located in the so-called Tangled Hills (or Encounter Hills), visited by the rover on the second lunar day of its journey. The lowest point $(-2773 \mathrm{~m})$ was encountered on the western side of Fossa Recta during the fourth lunar day (Fig. 13c). Here, the rover encountered maximum slopes at an angle of $20.3^{\circ}$ measured on a baseline of $5 \mathrm{~m}$. The total range of elevations along the Lunokhod-2 traverse is $144 \mathrm{~m}$.

Table 5. Slope analysis for the Lunokhod area

\begin{tabular}{|c|c|c|}
\hline Slopes, $^{\circ}$ & Area, $^{\mathbf{~ k m}}{ }^{\mathbf{2}}$ & \% \\
\hline $0-7$ & 209.9 & 81.7 \\
\hline $7-15$ & 29.0 & 11.3 \\
\hline $15-25$ & 15.3 & 6.0 \\
\hline$>25$ & 2.6 & 1.0 \\
\hline Total & $\mathbf{2 5 6 . 8}$ & $\mathbf{1 0 0}$ \\
\hline
\end{tabular}

The slope analysis for the Lunokhod-2 area has been done using the DEM (Table 5). For spacecraft landing safety, a rather flat area was chosen for the Luna-21 module near the south rim of Le Monnier crater. Most slopes do not exceed $7^{\circ}$ (about 82\%); slopes of $7-15^{\circ}$ are infrequent $(\sim 11 \%)$; areas with steep slopes $\left(15\right.$ up to $\left.25^{\circ}\right)$ are rare $(7 \%)$, and high slopes almost never occur $(1 \%)$. 


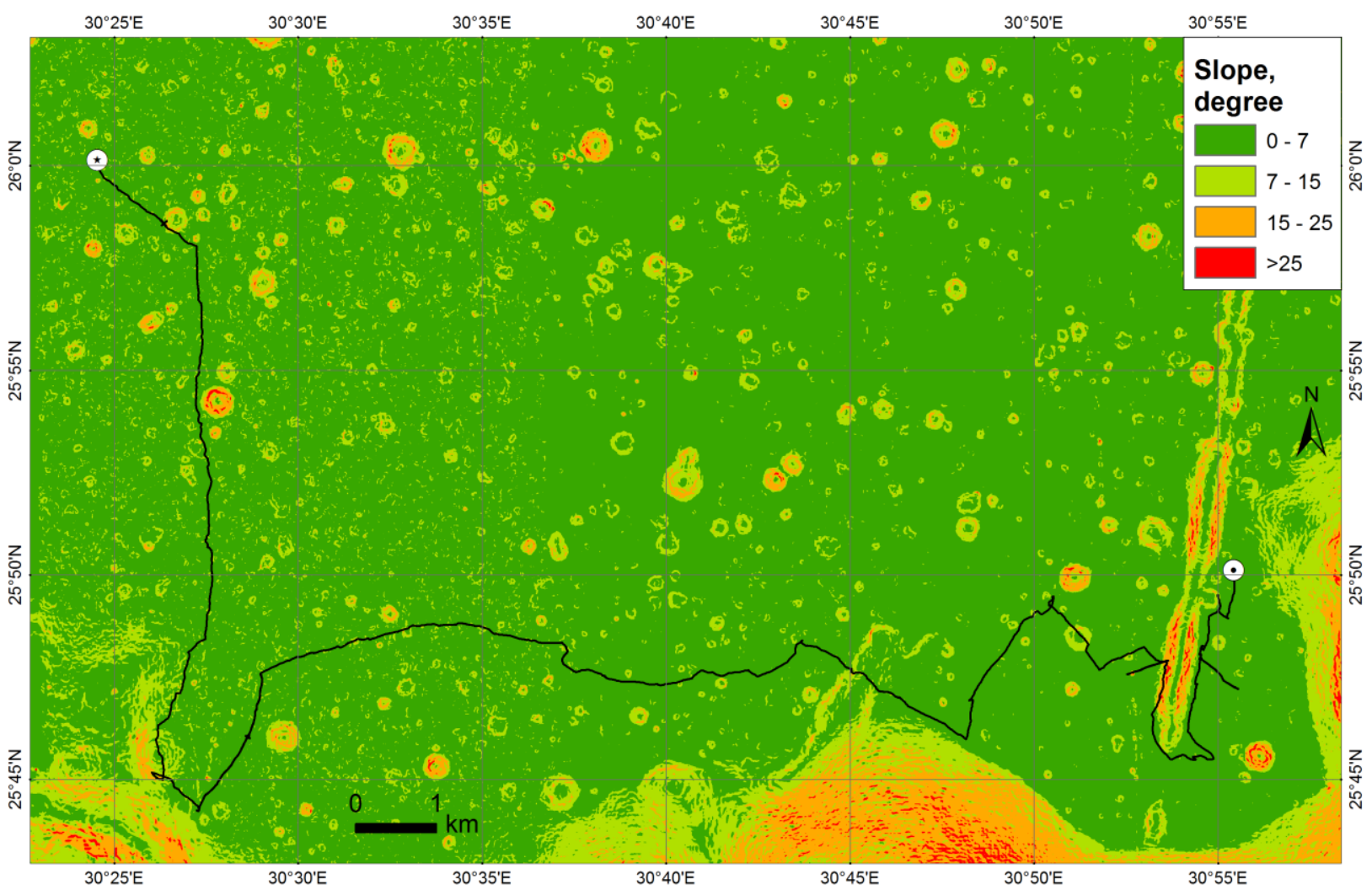

444

445

446

447

448

449

450

451

452

453

454

455

456

457

458

459

460

461

462

463

464

465

466

467

468

Figure 14. Slope map for the Lunokhod-2 area computed using NAC DEM on a baseline of $5 \mathrm{~m}$

Using the crater catalog for a small portion of the Lunokhod-2 area near Fossa Recta and the high-resolution DEM, a detailed morphometric study and analysis of degradation of small impact craters on the lunar mare was made by Basilevsky et al. (2014). The analysis of cumulative frequency distributions of depth/Diameter (d/D) of the studied craters and derived crater degradation rate revealed two different processes of crater degradation: one is rather rapid and affects craters with d/D larger than $\sim 0.14$ and the maximum slope of crater inner wall steeper than $\sim 25^{\circ}$; the other, significantly slower process, affects shallower craters with gentler slopes. Also, differences between obtained d/D of small impact craters with the earlier published values (Basilevsky, 1976) have been noted.

\subsection{Mission Time Line - Lunokhod-2}

The automated spacecraft Luna-21 landed January 1, 1973 in the eastern part of the Sea of Serenity, in the southern portion of Le Monnier crater $\left(30^{\circ} 24^{\prime} \mathrm{E}, 25^{\circ} 59^{\prime} \mathrm{N}\right)$, close to the edge of a $40 \mathrm{~m}$ crater. As for the landing of Luna-17, the engine of Luna-21 shut down only when the platform touched the lunar surface, not based on a signal from the gamma-altimeter "Quantum$2 "$ as was originally planned (Dovgan, 2015). After initial visual inspection of the site, the Lunokhod-2 rover descended to the lunar surface and began its journey, including scientific experiments and panorama surveying (Table 6-7). On the first lunar day, soon after landing, the first panoramas and navigation MKTV-images were taken and transmitted to the Earth showing the surroundings (Fig. 3-4).

Table 6. Lunokhod-2 overnight positions, measured in GIS

\begin{tabular}{|c|c|c|c|c|}
\hline $\begin{array}{c}\text { Lunar } \\
\text { night }\end{array}$ & Date & Longitude, $^{\circ}$ & Latitude, ${ }^{\circ}$ & Elevation, m \\
\hline 1 & $25.01 .1973-07.02 .1973$ & 30.43749 & 25.97351 & -2678 \\
\hline 2 & $23.02 .1973-08.03 .1973$ & 30.47531 & 25.76436 & -2657 \\
\hline 3 & $22.03 .1973-08.04 .1973$ & 30.84048 & 25.82145 & -2736 \\
\hline 4 & $22.04 .1973-08.05 .1973$ & 30.91493 & 25.82212 & -2769 \\
\hline
\end{tabular}


Initially, Lunokhod-2 moved southwards and on the second lunar day (February 2, 1973) it reached the Tangled Hills (the closest part of the rim of Le Monnier crater). There, the Lunokhod-2 traveled uphill and studied the highlands. The main scientific goals of the mission were to study the transition zone between the mare and highlands and to examine prominent geologic features of the Fossa Recta (to the east from the landing site). Methods of study of the lunar surface were based on operational experience of Lunokhod-1 (Florensky et al., 1978). The approach combined detailed studies at selected points on the surface and studies along the traverse. The results of the detailed local studies can be considered as reference points and extrapolated along the corresponding part of the traverse. Comparison of quantitative characteristics obtained at such reference points shows changes in the surface properties along the traverse.

481

Several magnetic measurements were made during the mission (Dolginov et al., 1976). The magnetometer was mounted on a rod $1.5 \mathrm{~m}$ away from the rover; however, electrical currents inside the Lunokhod created magnetic fields that influenced the instrument readings. To eliminate this influence and perform the measurements, the rover moved away from the crater in four mutually perpendicular directions, and then returned (Fig. 15a). The magnetic experiments were conducted at several craters. For example, at the beginning of 2 nd and 3rd lunar days (Fig. 15a) and also on the 4th day near Fossa Recta (Fig. 15b,c). This procedure allowed the scientists to measure magnetic parameters of crater slopes, rim, and ejecta, and improved the accuracy of measurements. The experiments revealed that the Moon has a weak magnetic field, but local variations in the direction and intensity of the magnetic field are significant (Ivanov et al., 1977). These results are used to compare the measurements obtained by portable magnetometer during the Apollo missions (Vanyan et al., 1979).
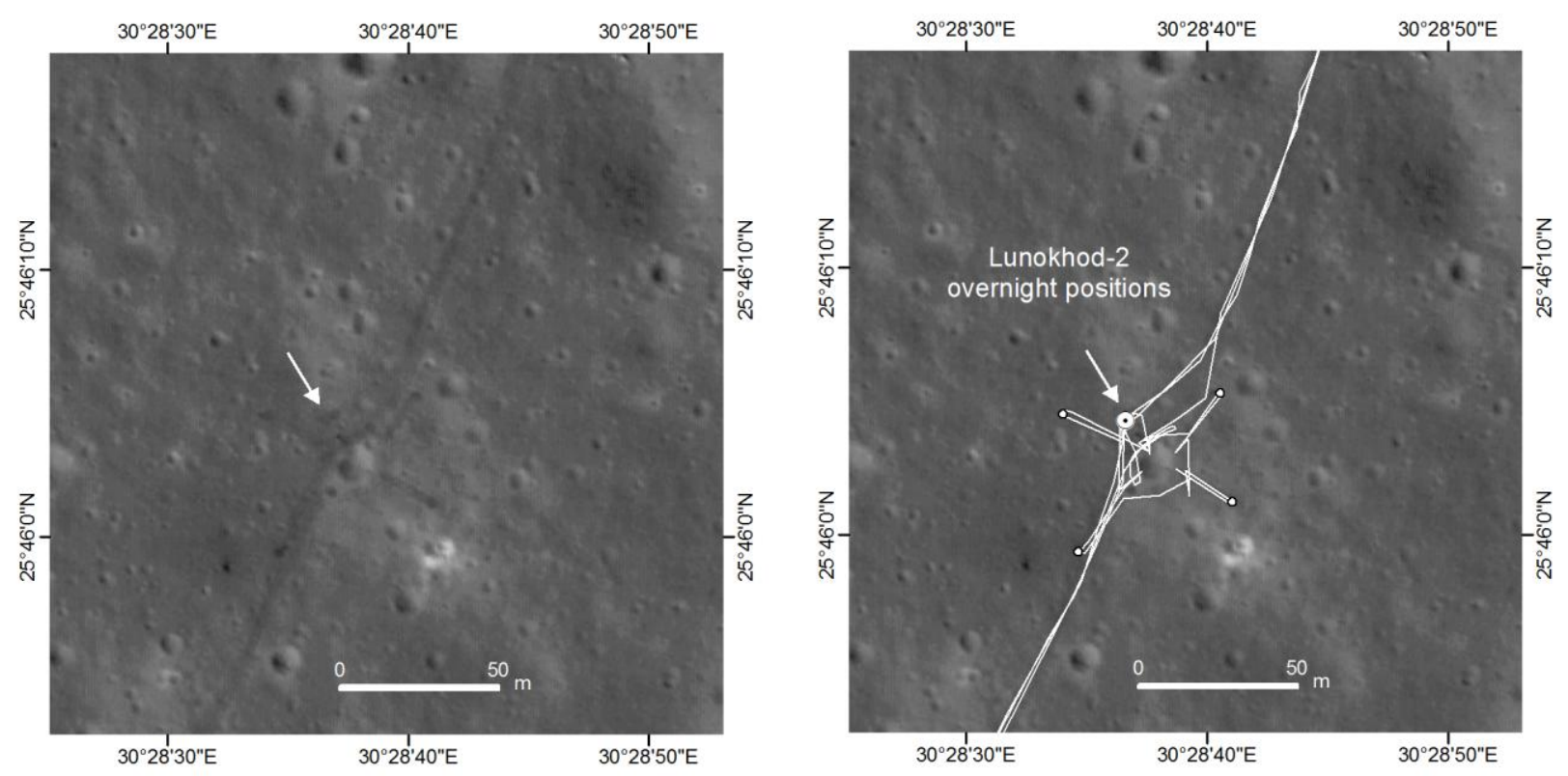

a) 

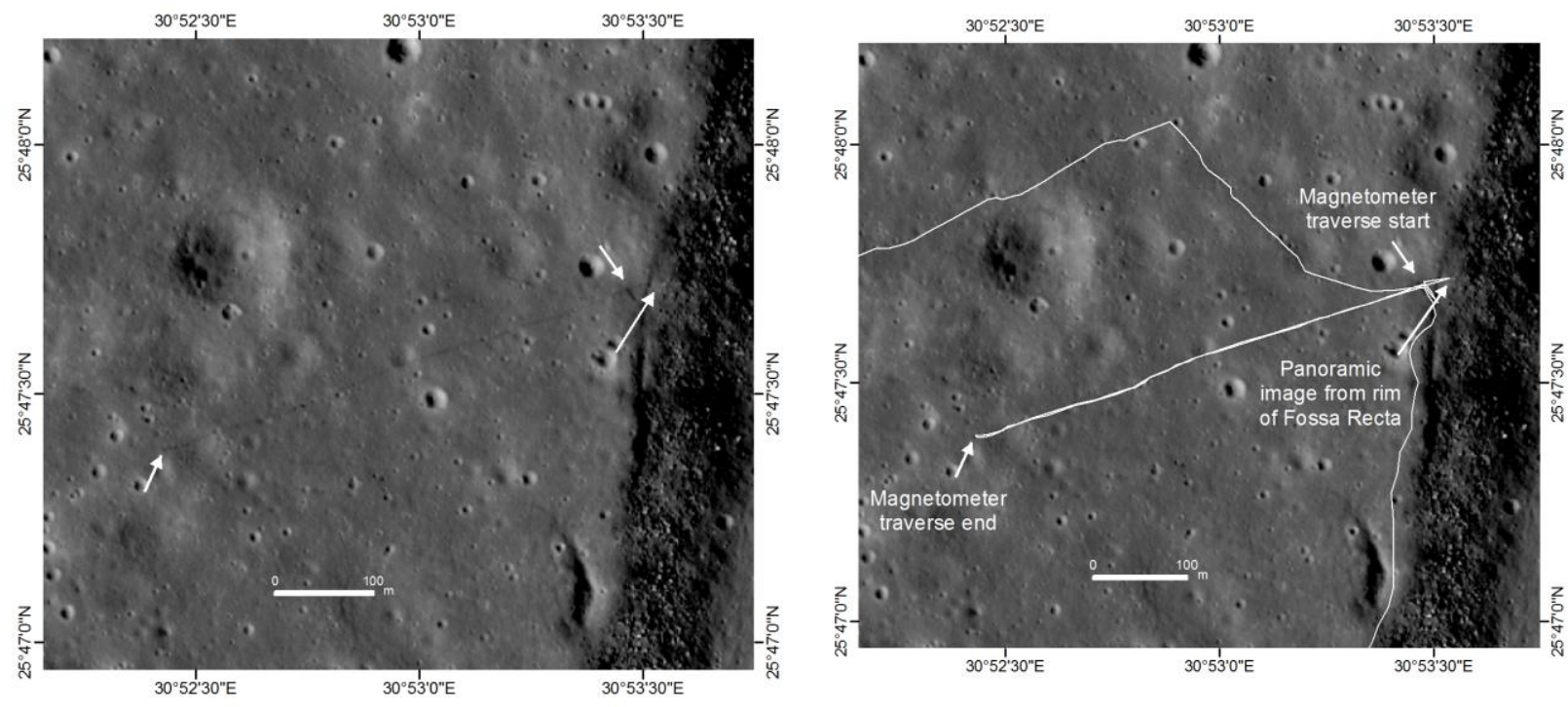

b)
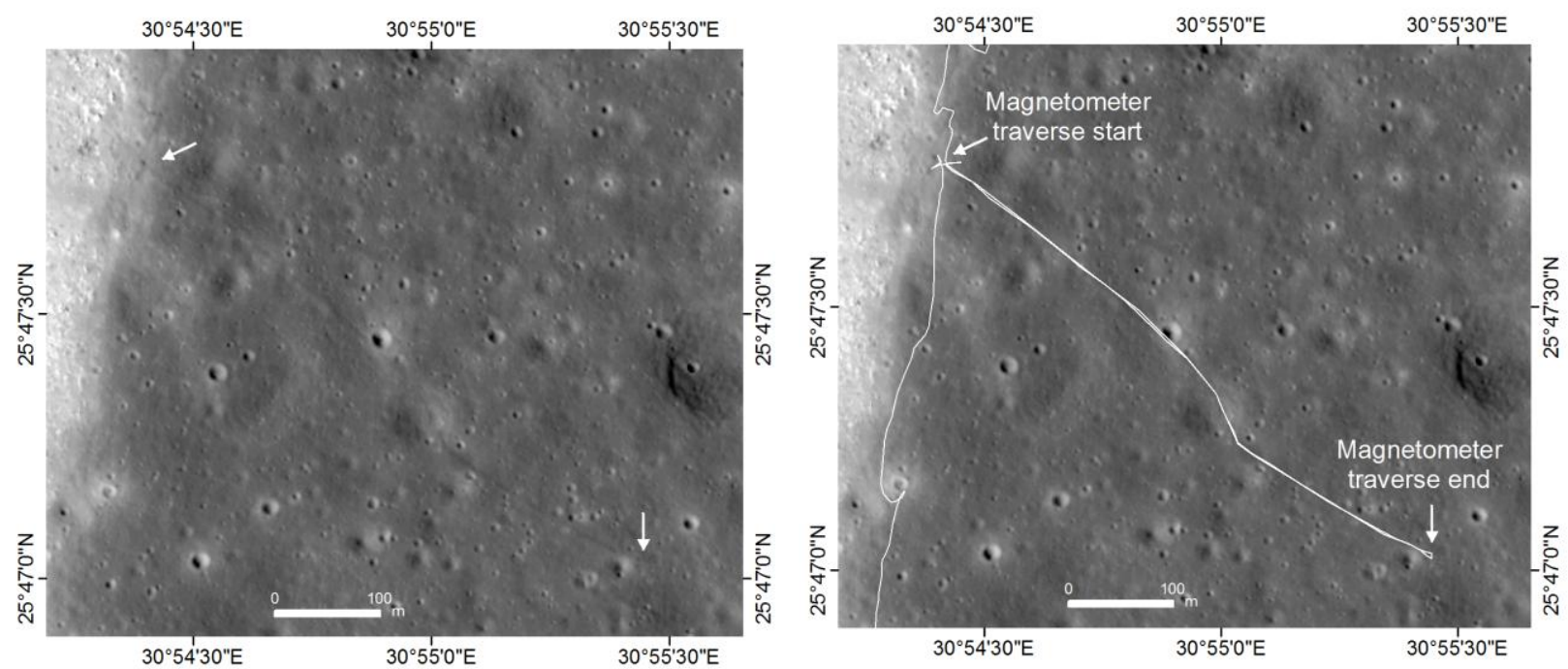

c)

494

495

496

497

498

499

500

501

502

503

504

505

506
Figure 15. Enlarged portions of the Lunokhod-2 route. The left images represent scenes from the original mosaic while the right show highlights of various stops and traverses from the Lunokhod-2 mission: a) the southwest magnetometer traverse where the rover moved three times along this same traverse; b) the west magnetometer traverse near Fossa graben; and c) the east magnetometer traverse near Fossa graben.

Implementing the traverses for the magnetometer measurements was a complex navigation task. Thus, while performing the experiment on the second lunar day, the Lunokhod-2 traveled 364 meters and made 120 different maneuvers, working 11 hours around a crater having a 15-m diameter (Dovgan, 2015). The complexity of navigation around of the another crater with the same diameter is shown in Fig. 16a, based on MKTV-images, transmitted during the third lunar day, that have much lower quality than the panoramas (Fig. 16b). 

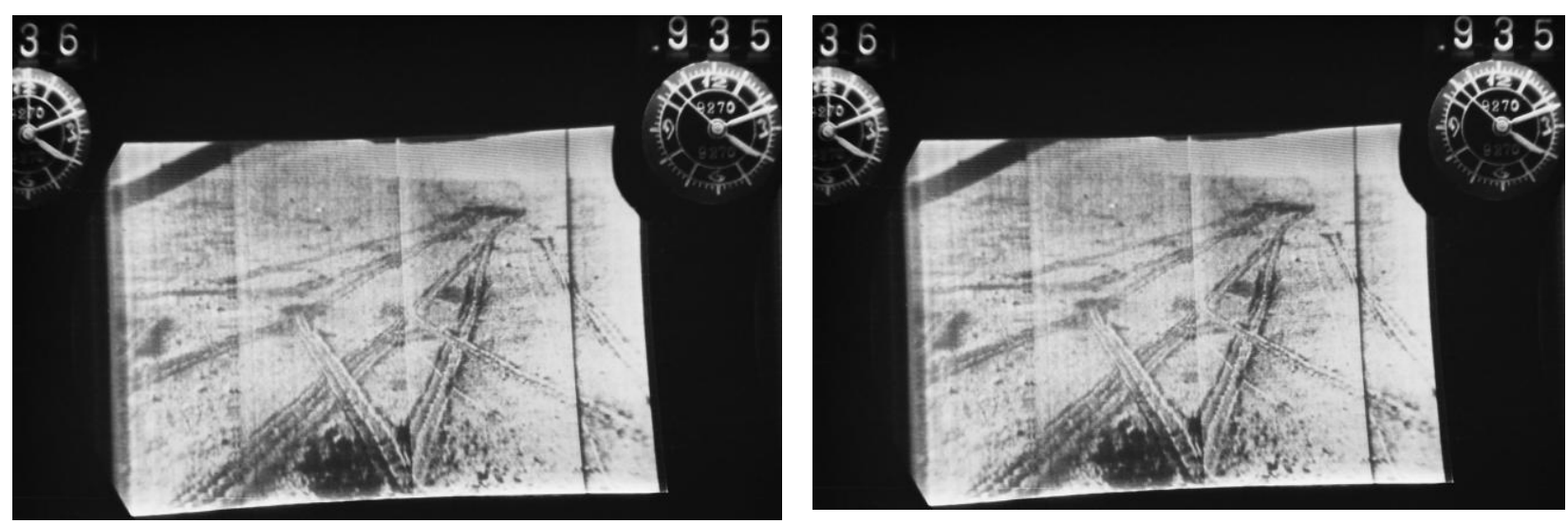

a)

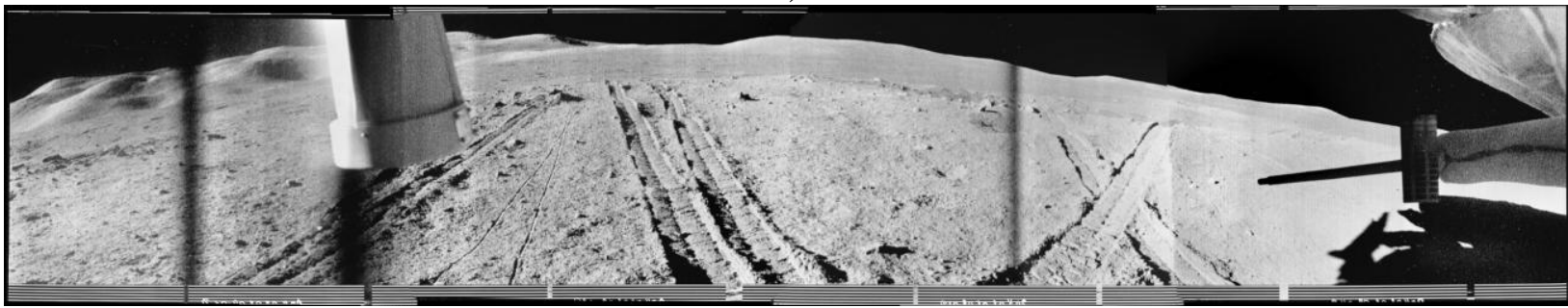

b)

509

Figure 16. Images taken by Lunokhod-2 navigation and panoramic cameras during the magnetic experiment on the third lunar day: a) examples of MKTV-images; b) newly assembled archive panorama \# 6-387 shows tracks of the rover and its ninth wheel.

After completion of the magnetic experiments on the third lunar day, the rover returned to the mare and moved eastward toward the Fossa Recta graben. Lunokhod-2 produced two distance records on this day, covering $17.6 \mathrm{~km}$ during 10 sessions (16.6 km according to measurements at the time of the mission) as well as covering $3130 \mathrm{~m}$ in one session (Dovgan, 2015). In contrast, the entire Lunokhod-1 traverse during 11 lunar days was $9.9 \mathrm{~km}$ as derived from recent GIS-measurements (Karachevtseva et al., 2013), which also differ from the measurements at the time of the mission by $\sim 0.5 \mathrm{~km}$.

Table 7. Lunokhod-2 points of interest, measured in GIS

\begin{tabular}{|c|c|c|c|c|c|c|}
\hline No & $\begin{array}{c}\text { Lunar } \\
\text { day }\end{array}$ & Date & Description & $\begin{array}{c}\text { Longitude, } \\
\circ\end{array}$ & $\begin{array}{c}\text { Latitude, } \\
\circ\end{array}$ & $\begin{array}{c}\text { Elevation, } \\
\text { m }\end{array}$ \\
\hline 1. & 1 & 16.01 .1973 & $\begin{array}{c}\text { Landing site: First } \\
\text { panoramic images taken } \\
\text { from Luna-21 module (6- } \\
364-6-367) *\end{array}$ & 30.40754 & 25.99910 & -2677 \\
\hline 2. & 1 & $16.01 .1973-$ & $\begin{array}{c}\text { The first panorama } \\
\text { obtained from the lunar } \\
\text { surface by Lunokhod-2: } \\
\text { 6-368 (Fig.4) }\end{array}$ & 30.40705 & 25.99947 & -2678 \\
\hline 3. & 1 & 18.01 .1973 & & & \\
\hline 4. & 2 & $18.01 .1973-$ & $\begin{array}{c}\text { Panoramic images near } \\
\text { Luna-21 landing module: } \\
\text { 6-370-6-374 }\end{array}$ & 30.40776 & 25.99926 & -2678 \\
\hline & 09.02 .1973 & $\begin{array}{c}\text { RIFMA experiment and } \\
\text { the first special magnetic } \\
\text { experiment. } \\
\text { Panoramas 6-386-6- }\end{array}$ & 30.43749 & 25.97350 & -2678 \\
\hline
\end{tabular}




\begin{tabular}{|c|c|c|c|c|c|c|}
\hline & & & 393 & & & \\
\hline 5. & 2 & $\begin{array}{l}11.02 .1973- \\
12.02 .1973\end{array}$ & RIFMA experiment & 30.45223 & 25.90731 & -2671 \\
\hline 6. & 2 & 12.02 .1973 & RIFMA experiment & 30.45234 & 25.89795 & -2670 \\
\hline 7. & 2 & $\begin{array}{l}12.02 .1973- \\
16.02 .1973\end{array}$ & RIFMA experiment & 30.45742 & 25.87743 & -2670 \\
\hline 8. & 2 & 19.02.1973 & $\begin{array}{l}\text { Maximum elevation on } \\
\text { the route } \\
\text { RIFMA experiment }\end{array}$ & 30.44376 & 25.74316 & -2629 \\
\hline 9. & 3 & 12.03 .1973 & $\begin{array}{l}\text { The second special } \\
\text { magnetic experiment. } \\
\text { RIFMA experiment. } \\
\text { Panoramas 6-416-6- } \\
424\end{array}$ & 30.47489 & 25.76455 & -2658 \\
\hline 10. & 2,3 & $\begin{array}{l}\text { 19.02.1973, } \\
13.03 .1973\end{array}$ & $\begin{array}{l}\text { South point of tripled } \\
\text { traverse, crater with } \\
\text { landslides. } \\
\text { RIFMA experiment. } \\
\text { Panoramas 6-410 - 6- } \\
415\end{array}$ & 30.45239 & 25.73441 & -2653 \\
\hline 11. & 3 & 14.03 .1973 & $\begin{array}{l}\text { North point of tripled } \\
\text { traverse. } \\
\text { RIFMA experiment. }\end{array}$ & 30.48155 & 25.79006 & -2658 \\
\hline 12. & 3 & 15.03 .1973 & RIFMA experiment. & 30.54591 & 25.80803 & -2670 \\
\hline 13. & 3 & 16.03.1973 & RIFMA experiment. & 30.61975 & 25.79995 & -2694 \\
\hline 14. & 3 & 18.03.1973 & RIFMA experiment. & 30.72665 & 25.80347 & -2716 \\
\hline 15. & 3 & 21.03 .1973 & RIFMA experiment. & 30.84048 & 25.82145 & -2736 \\
\hline 16. & 4 & $\begin{array}{l}11.04 .1973- \\
15.04 .1973\end{array}$ & $\begin{array}{l}\text { West side of Fossa } \\
\text { Recta graben - start point } \\
\text { of magnetic experiment. } \\
\text { RIFMA experiment. } \\
\text { Panoramas 6-444 - 6- } \\
447\end{array}$ & 30.89129 & 25.79523 & -2764 \\
\hline 17. & 4 & $\begin{array}{l}10.04 .1973- \\
15.04 .1973\end{array}$ & $\begin{array}{l}\text { West side of Fossa } \\
\text { Recta graben - end point } \\
\text { of magnetic experiment. }\end{array}$ & 30.87385 & 25.78983 & -2749 \\
\hline 18. & 4 & $\begin{array}{l}15.04 .1973- \\
16.04 .1973 \\
\end{array}$ & $\begin{array}{l}\text { Minimum elevation on } \\
\text { the route. }\end{array}$ & 30.89013 & 25.78517 & -2773 \\
\hline 19. & 4 & $\begin{array}{l}16.04 .1973- \\
20.04 .1973\end{array}$ & $\begin{array}{l}\text { East side of Fossa Recta } \\
\text { graben - start point of } \\
\text { magnetic experiment. } \\
\text { RIFMA experiment. } \\
\text { Panoramas 6-448 - 6- } \\
450\end{array}$ & 30.90668 & 25.79656 & -2762 \\
\hline 20. & 4 & $\begin{array}{l}16.04 .1973- \\
20.04 .1973\end{array}$ & $\begin{array}{l}\text { East side of Fossa Recta } \\
\text { graben - end point of } \\
\text { magnetic experiment. }\end{array}$ & 30.92409 & 25.78380 & -2763 \\
\hline 21. & 5 & 10.05 .1973 & $\begin{array}{l}\text { Final position of } \\
\text { Lunokhod-2 }\end{array}$ & 30.92211 & 25.83233 & -2761 \\
\hline
\end{tabular}

* ID of panoramic images based on ID of image fragments using by Russian State Archive 
The rover stopped for the third night about $1.5 \mathrm{~km}$ from the graben Fossa Recta $(\sim 19 \mathrm{~km}$ length, $400 \mathrm{~m}$ width, $\sim 20-50 \mathrm{~m}$ depth). During the fourth lunar day, on reaching Fossa Recta, Lunokhod-2 took several panoramas and made measurements of the magnetic field (Fig.15b). During this day the rover succeeded in traversing around the southern edge of the graben and traveling northward along its eastern rim. The magnetic field was measured in symmetric locations on the western and eastern side, providing nearly full magnetic profile of the area surrounding Fossa Recta (Fig.15c).

During four lunar days Lunokhod-2 traversed a total of $38.1 \mathrm{~km}$. The fifth lunar day was the last of the Lunokhod-2 journey and covered a distance of $\sim 1 \mathrm{~km}$. The final signal from Lunokhod-2 came on May 10, 1973. Lunokhod-2 parked facing southeast with the lid still open (see Fig. 17). Rover tracks approach from the north to the final parking place. The inset of Fig.17 is a zoomed-in view of the rover.

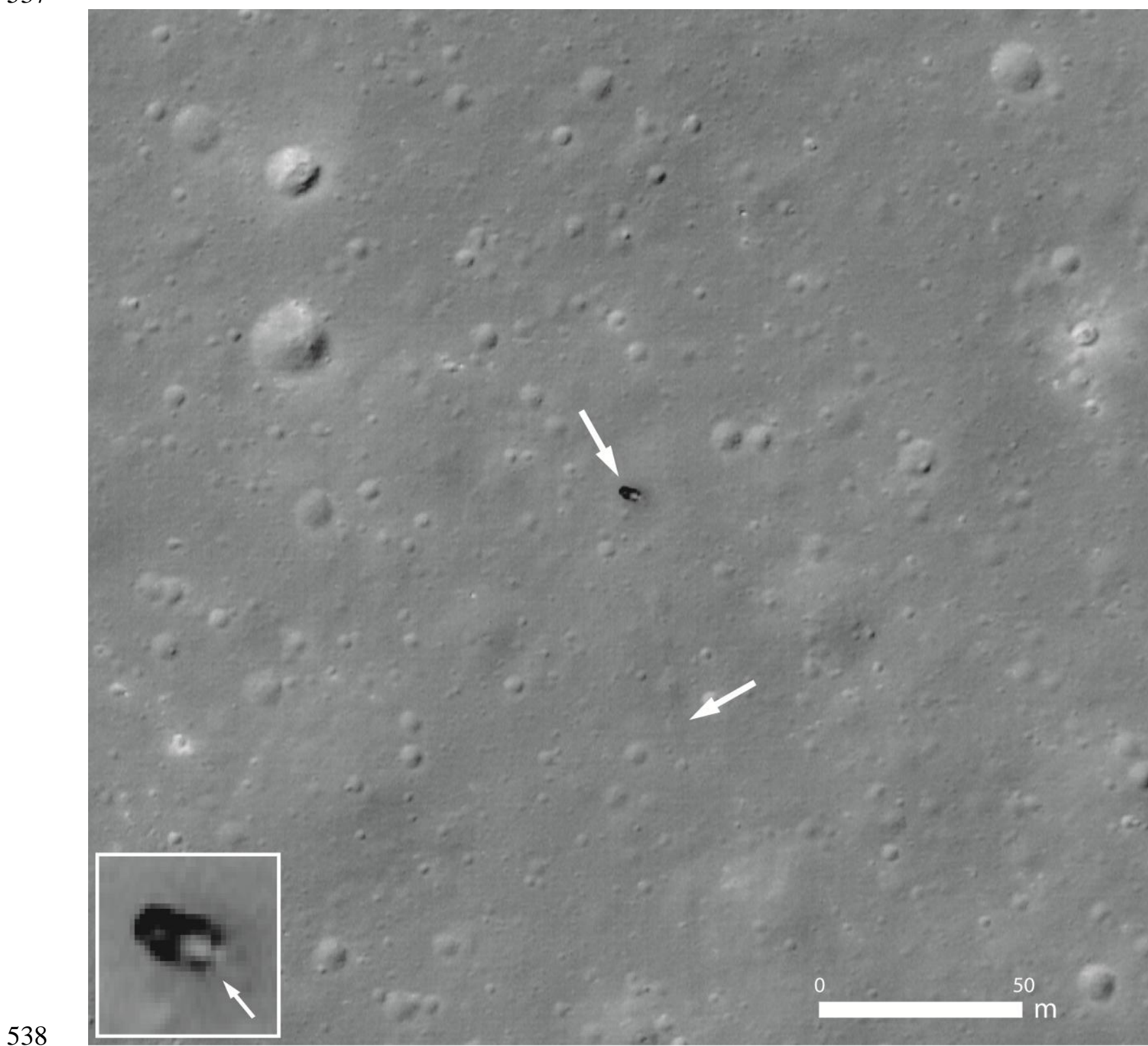

\section{Conclusions}


We report on Lunokhod-2 traverse measurements based on photogrammetrically processed NAC images that were used to map the study region (Fig. 18). Using GIS tools we reconstructed the rover traverse and derived improved locations for points of interest (Table 7) that provide new insights into mission achievements. Lunokhod-2 traversed a total distance of $39.1 \mathrm{~km}$ (compared with the previous estimate of $37 \mathrm{~km}$ ); the traverse was four times longer than that of Lunokhod-1.

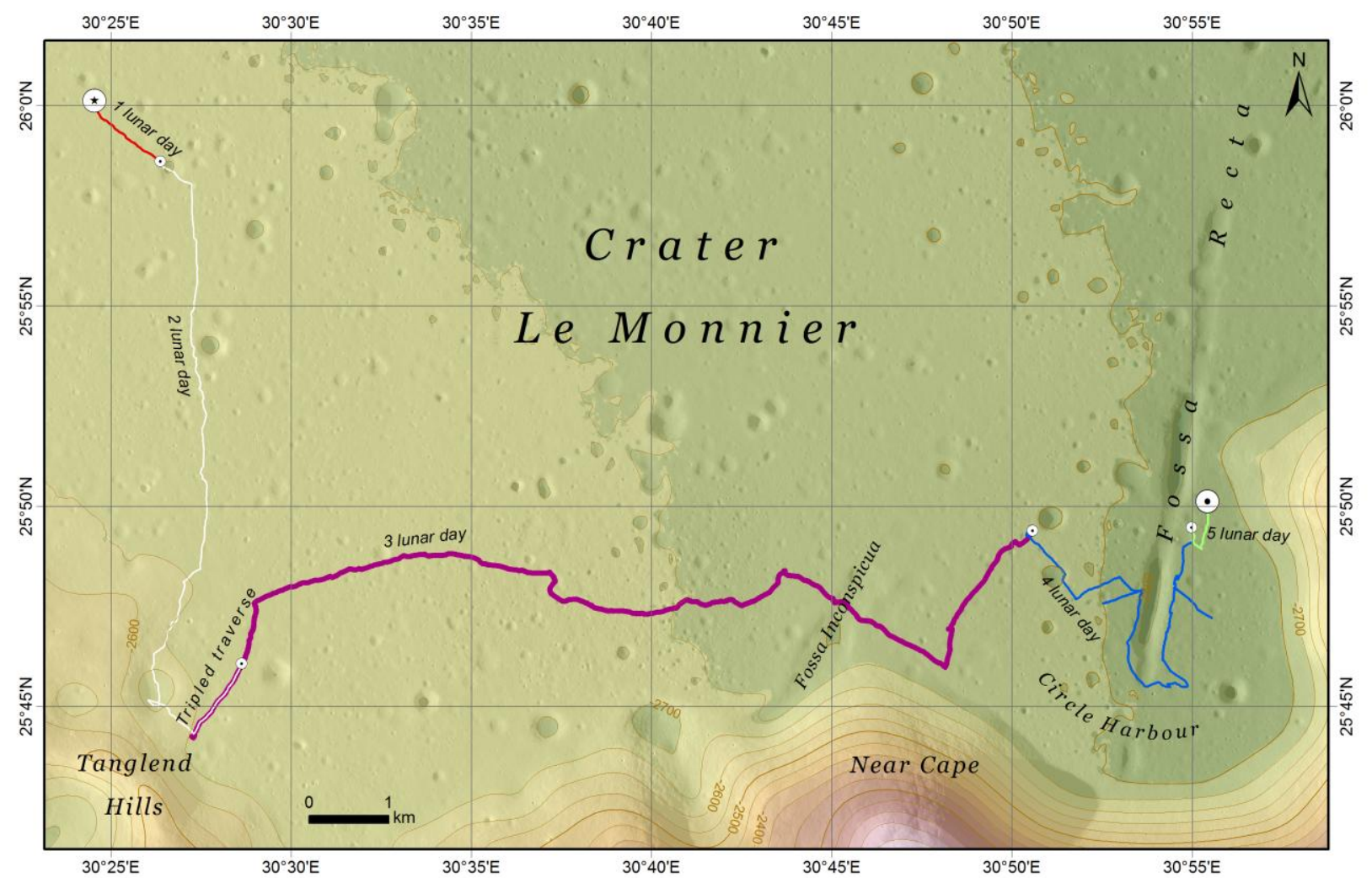

551

552

553

554

555

556

557

558

559

560

561

562

563

Figure 18. Hypsometric map of the Lunokhod-2 study area, based on new DEM and orthomosaic.

The main goals of the Lunokhod-2 mission were to investigate the morphology of the transition zone between lunar mare and highland terrains based on the surface panoramic images (Fig. 19a,b). Magnetometer measurements showed variations in the surface magnetic field, suggesting the induction of currents in the Moon under the influence of the changing interplanetary field. Based on laser ranging measurements to the reflector of Lunokhod-2, the rover's final position is one of the best known positions on the Moon, which is used for establishment of the lunar coordinate frame (Archinal et al., 2011) and for studies in lunar orbital and rotational dynamics (Kopeikin et al., 2008).

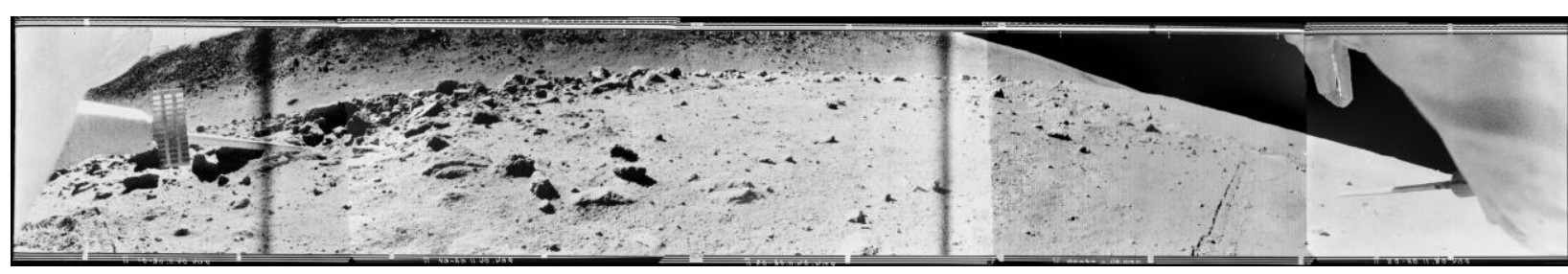

a) 


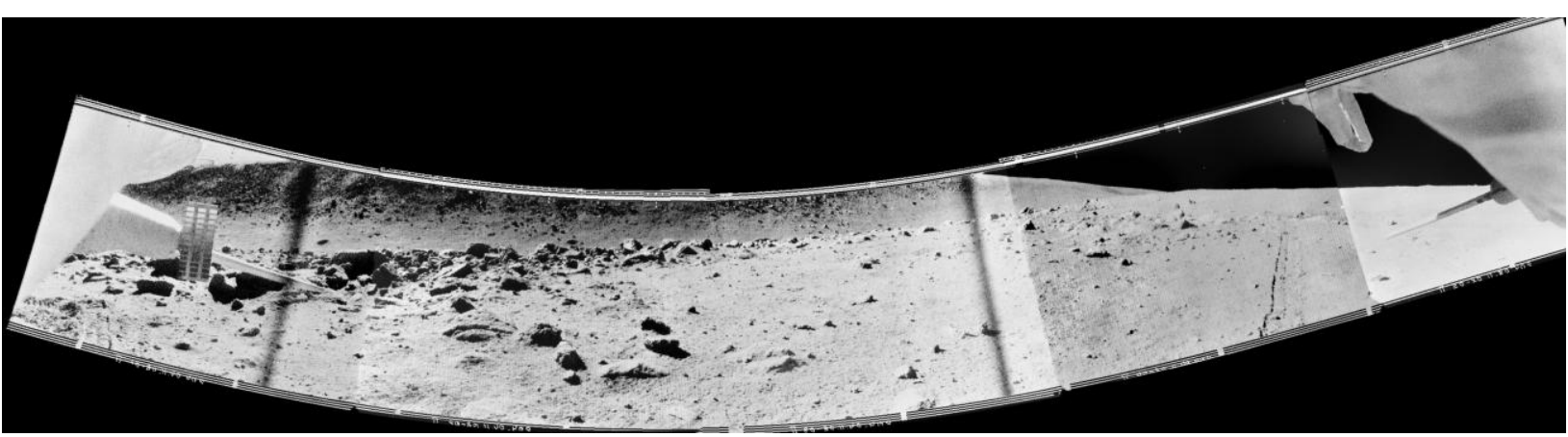

b)

Figure 19. Example one of the last Lunokhod-2 images (\#6-448), taken near Fossa Recta: a) result of new digital assembly of an archive panorama in spherical projection; b) the same assembled panorama image, which was photogrammetrically transformed to the horizon.

The DEM, the orthomosaic, and the digitized rover route were used to determine the Lunokhod-2 panorama observation points and for georeferencing of the panoramas in the frame of the PRoViDE project (http://www.provide-space.eu/), which focused on assembling a major portion of the imaging data gathered so far from vehicles and probes on planetary surfaces into a unique geodatabase.

Bringing archive data into modern spatial context provides excellent opportunities for detailed comparative analysis with new data. It provides a new view on past and recent lunar missions as, for example, studies of Lunokhod-1 and Yutu working areas (Basilevsky et al., 2015), including morphometric and geologic assessment, estimations of boulder types and densities, crater classes, and regolith structure. Moreover, the well-studied lunar regions can be used for future missions as an analog for testing and calibration of different instruments and techniques. For example, high-resolution DEMs and orthomosaics of the Lunokhod-1 and 2 areas support morphometric and safety assessments for selection of candidate Luna-25 (Luna-Glob) landing sites. There is a considerable amount of shadow in polar areas and there is no opportunity to obtain good quality stereo pairs for photogrammetrically processed DEMs. Therefore, a method of estimating the distribution of slopes in portions of shaded areas measured in the images acquired at different solar incidence angles was suggested (Abdrakhimov et al., 2015). This method was calibrated on analog regions in Lunokhod-1 and 2 areas where we have images with various illumination conditions as well as detailed DEMs. Furthermore, the LLR coordinates of the Lunokhod-1 and 2 rover positions provide high absolute accuracy of the created DEMs that can be used as a reference area to control calibration of the stereo camera for planned Russian Moon projects and to perform refinement of the spacecraft trajectory during the future orbital mission Luna-26 (Luna-Resource).

All digital data products shown in this paper derived from LROC NAC processing as well as newly assembled lunar archive panoramas georeferenced to Lunokhod traverse can be found at MIIGAiK Planetary Data Geoportal (http://cartsrv.mexlab.ru/geoportal/).

\section{Acknowledgements:}

The authors greatly acknowledge useful discussions with G.A. Burba. Also, we wish to thank V.G. Dovgan, member of Lunokhod-1,2 crew, one of the two drivers who operated the rover remotely, and provided accounts and insights on the Lunokhod missions. We acknowledge and appreciate the work of Ryan Clegg-Watkins and Michael Zanetti at Washington University in St. Louis to trace the Lunokhod-2 tracks in NAC images and for their help in determining the correct traverse distance. Bob Craddock (Smithsonian Institution) and an anonymous reviewer provided valuable comments, which improved an earlier version of this manuscript.

I.P. Karachevtseva, N.A. Kozlova, A.A. Kokhanov, A.E. Zubarev, I.E. Nadezhdina, V.D. Patratiy, A.A. Konopikhin, A.T. Basilevsky and J. Oberst are supported by the Russian Science Foundation (project № 14-22-00197). 
The processing of archive lunar panoramas received funding from the European Community's Seventh Framework Programme (FP7/2007-2013) under grant agreement № 312377 PRoViDE.

613

We wish to thank the Russian State Archive for access and permission to use the scanned

614

615

616

617

618

619

620

621

622

623

624

625

626

627

628

629

630

631

632

633

634

635

636

637

638

639

640

641

642

643

644

645

646

647

648

649

650

651

652

653

654

655

656

657

658

659

660 row images.

\section{References:}

Abdrakhimov A.M., Basilevsky A.T., Head J.W., Robinson M.S. Luna 17/ Lunokhod 1 and Luna 21/Lunokhod 2 landing sites as seen by the Lunokhod and LRO cameras. 2011. 42nd Lunar and Planetary Science Conference. Abstract \#. 1608, p. 2220.

Abdrakhimov A.M., Basilevsky A.T., Ivanov M.A., Kokhanov A.A., Karachevtseva I.P., Head J.W., 2015. Occurrence probability of slopes on the lunar surface: estimate by the shaded area percentage in the LROC NAC images. Solar System Research, V. 49, N. 5, pp. 285-294, doi: $10.1134 / \mathrm{S} 0038094615050019$

Abdrakhimov, A.M. Re-examine Lunokhod Sites: old and new geochemical data. 40th Lunar and Planetary Science Conference. 2009. Abstract \#2547.

Adrov V.N, Chekurin A.D, Sechin A.Yu, Smirnov A. N, Adam-Guillaume J.-P, Quessete J.-P. Program PHOTOMOD: digital photogrammetry and stereoscopic image synthesis on a personal computer. (1995) In: Proc. SPIE, 2646. Digital Photogrammetry and Remote Sensing'95 (Ed: Fedosov E.A.), pp. 89-96. doi:10.1117/12.227853.

Anderson, J.A., Sides, S.C., Soltesz, D.L., Sucharski, T.L., Becker, K.J. (2004) Modernization of the Integrated Software for Imagers and Spectrometers. Lunar Planet. Sci. 35, \#2039.

Anisov K.S., Mastakov V.I., Ivanov O.G., and 15 co-authors. General design and assembling of Luna 17 spacecraft. In: Mobile Laboratory on the Moon Lunokhod-1, Vol.1. Vinogradov A.P. (Ed.) Nauka, 1971. pp.7-20, (in Russian).

Archinal B.A., A'Hearn M.F., Bowell E., Conrad A., Consolmagno G.J., Courtin R., Fukushima T., Hestroffer D., Hilton J. L., Krasinsky G.A., Neumann G., Oberst J., Seidelmann P.K., Stooke P., Tholen D.J., Thomas P.C. и Williams I.P. (2011). Report of the IAU working group on cartographic coordinates and rotational elements: 2009 // Celestial Mechanics and Dynamical Astronomy, т. 109, № 2, 2011, pp. 101-135.

Barsukov V.L. (ed.) Mobile laboratory on the Moon Lunokhod-1, Vol. 2. Moscow, Nauka, 1978, p. 183 (in Russian).

Basilevsky A. T., Kreslavsky M. A., Karachevtseva I. P., Gusakova E. N. Morphometry of small impact craters in the Lunokhod-1 and Lunokhod-2 study areas. Planetary and Space Science 92. - 2014. - pp. 77-87.

Basilevsky A.T. On the evolution rate of small lunar craters. 1976, Proc. Lunar Sci. Conf. 7th, 1005-1020.

Basilevsky A.T., Abdrakhimov A.M., Head J.W., Pieters C.M., Wu Y., Xiao L. Geologic characteristics of the Luna 17/Lunokhod 1 and Chang'E-3/Yutu landing sites, Northwest Mare Imbrium of the Moon // Planetary and Space Science, 2015, Volume 117, p. 385-400. DOI: 10.1016/j.pss.2015.08.006

Basilevsky A.T., Abdrakhimov A.M., Ivanov M.A., Zabalueva E.V., Karachevtseva I.P., Shingareva K.B., Gusakova E.N., Oberts J., Warhlisch M., Robinson M. 2012, Identification and measurements of small impact craters in the Lunokhod 1 study area, Mare Imbrium. LPSC-43, abs. 1481.

Becker K.J., Archinal B.A., Hare T.M., Kirk R.L., Howington-Kraus E., Robinson M.S., Rosiek M.R. Criteria for automated identification of stereo image pairs. 2015, Abstract 46th Lunar and Planetary Science Conference, \#2703.

Beigman I.L., Vainshtein L.A., Vasiliev B.N., Ivanov V.D., Mandelstam S.L., Savelyev V.A., Tindo I.P., Schaeffer E.K., Shurigin A.I. X-ray collimator telescope RT-1. In: Mobile 

141 (in Russian).

Cherkasov I.I., Shvarev V.V. 1975. Lunar ground. Moscow, Nauka. 142 p (In Russian).

665 Exhaust on Lunar Soil Reflectance Properties, Icarus, 227, doi:10.1016/j.icarus.2013.09.013.

Dickey J.O., Bender P.L., Faller J.E., Newhall X.X., Ricklefs R.L., Ries J.G., Shelus P.J., Veillet C., Whipple A.L., Wiant J.R., Williams J.G., Yoder C.F. Lunar laser ranging: a continuing legacy of the Apollo program. Science, 1994, V. 265, pp. 482-490.

Dolginov Sh.Sh., Yeroshenko Ye.G., Shapova V.A., Vnuchkova T.A., Vanyan L.L., Okulessky B.A., Basilevsky A.T. Study of magnetic field, rock magnetization and lunar electrical conductivity in the Bay Le Monnier. The Moon, 15, 1976, 3-14.

Dovgan V.G. The Moon Odysseus of Soviet Cosmonautics'. From "Mechta" ("Dream") to the Moon Rovers. Southern Federal University, Rostov-on-Don, 2015. - 307 p. (in Russian).

Elenov A.I., Rybin A.M., Yakovlev A.S. Thermal conditions and temperature control system. In: Mobile laboratory on the Moon Lunokhod-1. Vol.1. (Ed. Vinogradov A.P.) M.: Nauka, 1971, pp. 30-33 (in Russian).

Florensky K. P., Basilevsky A. T., Bobina N. N., Burba G. A., Grebeunik N. N., Kuzmin R. O., Polosukhin V. P., Popovich V. D., and Pronin A. A. 1976. Processes of the transformation of the lunar surface in the Le Monnier region studied using results of detailed investigations made by Lunokhod 2. In: Tectonics and structural geology. Planetology; International Geological Congress, Session, 25th, Sydney, Australia, August 16-25, 1976, Reports. (A7816366 04-91). Moscow, Nauka, 1976, p. 205-234 (in Russian).

Florensky K.P., Bazilevsky A.T., Gurshteyn A.A., Zasetskiy V.V., Pronin A.A., Polusuhin V.P. Geological and morphological analysis of the "Lunokhod-2" work area. Reports of the USSR Academy of Sciences. 1974, Vol. 214, №1, pp. 75-78 (in Russian).

Florensky K.P., Bazilevsky A.T., Zezin R.B., Polusuhin V.P., Popova Z.V. Geologic and morphologic study of lunar surface. In: Mobile laboratory on the Moon Lunokhod-1. Vol. 2. (Ed. Barsukov A.P.). M.: Nauka, 1978, pp. 102-135 (in Russian).

Grodecki J., Dial G. Block adjustment of high-resolution satellite images described by rational polynomials. 2003, Photogrammetric Engineering \& Remote Sensing, Vol. 69, No. 1, pp. 5968.

Gwinner, K., Robinson, M.S., LROC Team, 2010. Apollo 17 Landing Site Topography from LROC NAC Stereo Data - First Analysis and Results. 41st Lunar and Planetary Science Conference, Houston TX, March 2010, Abs. \#2051.

Haase, I., Oberst J., Scholten F., Wählisch M., Gläser P., Karachevtseva I., and Robinson M.S. Mapping the Apollo 17 landing site area based on Lunar Reconnaissance Orbiter Camera images and Apollo surface photography. 2011, J. Geophys. Res., Volume 117, Issue E12, doi: 10.1029/2011JE003908.

Hirschmüller H. Accurate and efficient stereo processing by semi-global matching and mutual information // Computer vision and pattern recognition, 2005. 2, pp. 807-814.

Huntress, W. T. and Marov M. Y., 2011, Soviet Robots in the Solar System, Springer Praxis Books, $453 \mathrm{pp}$.

Ivanov B. A., Okulessky B. A., and Bazilevsky A. T. 1977. Shock wave, a possible source of magnetic fields? // Eds. Roddy D.J., Pepin. R.O. and Merrill R.H. Impact and Explosion Cratering. Pergamon Press, New York. p. 861-867.

Karachevtseva I., Oberst J., Scholten F., Konopikhin A., Shingareva K., Cherepanova E., Gusakova E., Haase I., Peters O., Plescia J., Robinson M. Cartography of the Lunokhod-1 Landing Site and Traverse from LRO Image and Stereo Topographic Data. 2013, Planetary and Space Science, Vol.85, p. 175-187. http://dx.doi.org/10.1016/j.pss.2013.06.002.

Kemurdzhian A.L. (ed.) 1993. The Rovers. Moscow, Mashinostroenie. 400 p. (In Russian). 
Kemurdzhian A.L., Gromov V.V., Shvarev V.V. Investigation of physical and mechanical properties of extraterrestrial soil. In: Soviet achievements in space exploration 1967-1977 (Ed. Vernov S.N.) - Moscow, Nauka, 1978. pp. 352-380 (in Russian).

Kocharov G.E., Borodulin N.F., Viktorov S.V., Voropaev O.M., Dzevanovskaya A.Yu., Ivanov O.G., Kirian G.V., Petrov V.V., Sakulskiy V.A. Lunar automatic spectrometric equipment A.P.) M.: Nauka, 1971, pp. 89-95. (in Russian).

Kocharov G.E., Viktorov S.V. 1974. The chemical composition of the lunar surface in the work region of the Lunokhod-2. Reports of the USSR Academy of Sciences. Vol. 214, No. 1. pp.71-74. (in Russian).

Kokurin Yu.L. Lunar laser ranging. 40 years of research. Quantum Electronics. 2003. № 33 (1), pp. 45-47 (in Russian).

Kokurin Yu.L., Kurbasov V.V., Lobanov V.F., Sukhanovskii A.N., Chernykh N.S. Laser radar location experiment using light reflector mounted on the Lunokhod-1 vehicle. In: Mobile laboratory on the Moon Lunokhod-1. Vol.2 (Ed. Barsukov V.L.) M.: Nauka, 1978, pp. 170180 (in Russian).

Kopeikin S., Pavlis E., Pavlis D., Brumberg V., Escapa A., Getino J., Gusev A, Mueller J., Ni W., Petrova N. Prospects in the orbital and rotational dynamics of the Moon with the advent of sub-centimeter lunar laser ranging. 2008, Advances in Space Research, Vol. 42, Issue 8, pp. 1378-1390. doi:10.1016/j.asr.2008.02.014.

Kozlova N., Zubarev A., Karachevtseva I., Nadezhdina I., Kokhanov A., Patraty V., Mitrokhina L., and Oberst J. Some aspects of modern photogrammetric image processing of Soviet Lunokhod panoramas and their implementation for new studies of lunar surface. // The International Archives of the Photogrammetry, Remote Sensing and Spatial Information Sciences, 2014, Volume XL-4, 2014 ISPRS Technical Commission IV Symposium, Suzhou, China, doi:10.5194/isprsarchives-XL-4-121-2014. Kozlova_Lunokhod_DOI_panoramas_full_paper.pdf.,pp. 121-126.

Leonovich A.K. Ivanov O.G., Pavlov P.S., and 13 co-authors. Self-propelled chassis Lunokhod1 as a tool for the study of lunar surface. In: Mobile laboratory on the Moon Lunokhod-1. Vol. 2. (Ed. Barsukov A.P.). M.: Nauka, 1978, pp. 25-43 (in Russian).

Leonovich A.K., Gromov V.V., Rybakov A.V., Petrov V.K., Pavlov P.S. Cherkasov I.I., Shvarev V.V. Studies of the mechanical properties of lunar soil on self-propelled vehicle Lunokhod-1. In: Mobile laboratory on the Moon Lunokhod-1. Vol.1. (Ed. Vinogradov A.P.) M.: Nauka, 1971, pp. 78-88. (in Russian).

Lipskiy Yu.N., Rodionova Zh.F. Cartography of the Moon. In: Soviet achievements in space exploration 1967-1977 (Ed. Vernov S.N.) - Moscow, Nauka, 1978. pp. $406-434$ (in Russian). Mazarico E., Rowlands D.D., Neumann G.A., Smith D.E., Torrence M.H., Lemoine F.G., Zuber M.T., 2012. Orbit Determination of the Lunar Reconnaissance Orbiter, Journal of Geodesy, 86(3), 193-207. 10.1007/s00190-011-0509-4

Murphy Jr. T.W, E.G. Adelberger, J.B.R. Battat, C.D. Hoyle, R.J. McMillan, E.L. Michelsen, R.L. Samad, C.W. Stubbs, H.E. Swanson. 2010. Long-term degradation of optical devices on the Moon. Icarus 208, 31-35.

Murphy T.W., Adelberger E.G., Battat J.B.R., Hoyle C.D., Johnson N.H., McMillan R.J., Michelsen E.L., Stubbs C.W., and Swanson H.E. Laser ranging to the lost Lunokhod 1 reflector. 2011, Icarus, Volume 211, Issue 2, p. 1103-1108.

Oberst, J., Scholten, F., Matz, K.D., Roatsch, T., Wählisch, M., Haase, I., Gläser, P., Gwinner, K., Robinson, M.S., LROC Team, 2010. Apollo 17 Landing Site Topography from LROC NAC Stereo Data - First Analysis and Results. 41st Lunar and Planetary Science Conference, Houston TX, March 2010, Abs. \#2051.

Petrov Yu.A. Psychological problems of remote control. In: Mobile laboratory on the Moon Lunokhod-1. Vol. 2. (Ed. Barsukov A.P.). M.: Nauka, 1978, pp. 20-25 (in Russian). 
Researches of the Moon. Chapter 4. pp. 142-214. In: Development of a space in the USSR, 1973 (On press materials). Moscow, Nauka. 1975. 305 p. (in Russian).

Robinson M.S., Brylow S.M., Tschimmel M., Humm D., Lawrence S.J., Thomas P.C., Denevi B.W., Bowman-Cisneros E., Zerr J., Ravine M.A., Caplinger M.A., Ghaemi F.T., Schaffner J.A., Malin M.C., Mahanti P., Bartels A., Anderson J., Tran T.N., Eliason E.M., McEwen A.S., Turtle E., Jolliff B.L., Hiesinger H. 2010, the Lunar Reconnaissance Orbiter Camera (LROC) instrument overview. Space Sci. Rev. 150, pp.81-124.

Rodionov B.N. To the history of the lunar exploration by Soviet spacecraft // Proceedings of the International Symposium "The scientific results of space research of the Moon. 40th anniversary of the first images of Far side of the Moon". Moscow, Sternberg State Astronomical Institute, 1999. (in Russian).

Rodionov B.N., Nepoklonov B.V., Kiselev V.V. Topography study along the "Lunokhod-1" route. In: Mobile laboratory on the Moon Lunokhod-1. Vol.1. (Ed. Vinogradov A.P.) M.: Nauka, 1971, pp. 55-73. (in Russian).

Rodionov B.N., Nepoklonov B.V., Kiselev V.V., Selivanov A. S., Zasetskiy V.V., Ivanov O.G., Babakov F.I., Mikhailov R.M., Reshetov M.M. Topographical surveys on the lunar surface from the Soviet unmanned spacecrafts. 1973, Geodesy and Cartography, № 10. pp. 29-41 (in Russian).

Scholten F., Oberst J., Matz K.-D, Roatsch T., Wählisch M., Speyerer E. J, and Robinson, M. S. GLD100: The near-global lunar $100 \mathrm{~m}$ raster DTM from LROC WAC stereo image data // 2012, J. Geophys. Res. № 117, E00H17.

Sechin A. Dense DSM generation module in PHOTOMOD 6.0 // 2014, 14th International Scientific and Technical Conference "From imagery to map: digital photogrammetric technologies" Hainan, http://conf.racurs.ru/images/presentations/SECHIN_DSM_CHINA.ppsx.

Selivanov A.S., Govorov V.M., Zasetskii V.V., Timohin V.A. Construction properties and main parameters of Lunokhod-1 television systems. In: Mobile laboratory on the Moon Lunokhod1. Vol.1. (Ed. Vinogradov A.P.) M.: Nauka, 1971, pp. 55-65 (in Russian).

Severny A.B., Terez E.I., Zvereva A.M. The measurements of sky brightness on Lunokhod-2 // The Moon. - 1975. - Vol. 14. - P. 123-128.

Stooke Ph.J. The International Atlas of Lunar Exploration. 2007, Cambridge University Press. $440 \mathrm{p}$.

Vanyan L.L., Vnuchkova T.A., Egorov I.V., Basilevsky A.T., Eroshenko E.G., Fainberg E.B., Dyal P., and Daily W.D. (1979) Electrical conductivity anomaly beneath Mare Serenitatis detected by Lunokhod 2 and Apollo 16 magnetometers. Moon and Planets, 21, 185-192.

Vernov S.N., Lyubimov G.P., Chuchkov E.A., Kontor N.N. The study of cosmic rays. In: Mobile laboratory on the Moon Lunokhod-1. Vol.1. (Ed. Vinogradov A.P.) M.: Nauka, 1971, pp. 116-125.

Viktorov S.V., Chesnokov V.I. 1978. The chemistry of a lunar soil. / Series: Astronautics, Astronomy, No. 2. Moscow, Znanie. 64 p. (in Russian).

Vinogradov A.P. (ed.) Mobile laboratory on the Moon Lunokhod-1, Vol. 1. Moscow, Nauka, 1971. P. 128 (in Russian).

Vondrak, R., Keller J., Chin G., and Garvin J. Lunar Reconnaissance Orbiter (LRO): Observations for Lunar Exploration and Science, 2010, Space Sci. Rev., 150, 7-22, doi:10.1007/s11214-010-9631-5.

Wagner R.V., Robinson M.S., Speyerer E.J., Plescia J.B. Locations of Anthropogenic Sites on the Moon. 2014, 45th Lunar and Planetary Science Conference, Abstract \# 2259.

Williams J.G., Boggs D.H., Folkner W.M. DE430 Lunar orbit, physical librations, and surface coordinates // 2013, Jet Propulsion Laboratory, Report No. IOM 335-JW, DB, WF20130722-016. 
812 Zubarev A.E., Nadezhdina I.E., Kozlova N.A., Patratiy V.D. Special software for planetary 813 image processing and research // The International Archives of the Photogrammetry, Remote $814 \quad$ Sensing and Spatial Information Sciences, 2016 (in press).

\section{Web-references:}

http://cartsrv.mexlab.ru/geoportal/

http://naif.jpl.nasa.gov/naif/data.html

http://wms.lroc.asu.edu/lroc

820 http://www.esri.com/ http://www.laspace.ru/rus/luna21.html http://www.laspace.ru/rus/museum.php http://www.provide-space.eu/ http://www.racurs.ru/?page $=634$

https://isis.astrogeology.usgs.gov/ 